\title{
A Comparison of Family Policy Designs of Australia and Norway Using Microsimulation Models
}

\author{
Guyonne Kalb $^{\dagger *}$ and Thor O. Thoresen ${ }^{\ddagger}$ \\ † Melbourne Institute of Applied Economic and Social Research \\ The University of Melbourne, VIC 3010 \\ Australia \\ ¥ Research Department \\ Statistics Norway, Oslo \\ Norway
}

\begin{abstract}
Many of the Australian family support schemes are income-tested transfers, targeted towards the lower end of the income distribution, whereas the Norwegian approach is to provide subsidized non-parental care services and universal family payments. We contrast these two types of policies and discuss policy changes within these policy types by presenting results from simulations, using microsimulation models developed for Australia and Norway. Labor supply effects and distributional effects are discussed for the hypothetical policy changes of replacing the means-tested family payments of Australia by the Norwegian universal child benefit schedule and vice versa, and of reducing the childcare fees in both countries. The analysis highlights that the case for policy changes is restricted by the economic environment and the role of family policy in the two countries. Whereas there is considerable potential for increased labor supply of Australian mothers, it may have detrimental distributional effects and is likely to be costly. In Norway, mothers already have high labor supply and any adverse distributional effects of further labor supply incentives occur in an economy with low initial income dispersion. However, expenditure on family support is already high and the question is whether this should be further extended.
\end{abstract}

JEL codes: J22, H31, J13

Keywords: female labor supply, family policy, means-testing, childcare, microsimulation

* Corresponding author, e-mail: g.kalb@unimelb.edu.au, phone: +61 38344 2095, fax:

+61383442111. 


\section{Introduction}

There is substantial variation among countries in how family support schemes are designed. The effects of the "in-work" benefit systems of the UK and the US, the Working Families’ Tax Credit (WFTC) and the Earned Income Tax Credit (EITC), have received considerable attention, see for example, Blundell et al. (2000), Hotz and Scholz (2003), Eissa and Hoynes (2004), Brewer et al. (2006). In this paper we focus on policy changes within two other types of support schemes: the Nordic model of subsidized non-parental care and universal family income support versus a support scheme based on means-tested or incometested transfers.

The Norwegian family transfer system is used as an example of the first type of family support scheme. A combination of provision of low-fee center-based care options for families with two working parents and a universal child benefit schedule has been a key component of Norwegian family policy over several decades, whereas the income testing of family support schemes and childcare subsidies is the cornerstone of Australian family transfer programs. The Australian system differs from the WFTC and the EITC of the UK and the US, which also are income-tested transfers, in that qualification for the WFTC and EITC requires parents' employment; thus they are "in-work" benefits. Therefore, in terms of the relationship between support schemes and parents' labor supply, Norwegian and Australian programs represent two alternatives to the WFTC and the EITC.

The main purpose of this paper is to discuss effects of policy changes for families with preschool children within the two countries and within the two types of family transfer designs. There is a growing awareness of the need for labor supply in a situation of population ageing where a large proportion of the population may be unavailable for work in the future. However such ambitions are restricted by distributional concerns. Through the use of a labor supply and childcare model in the context of behavioral microsimulation models, which have been developed independently for Australia and Norway (Doiron and Kalb, 2005; Kalb and Lee, 2008; Kornstad and Thoresen, 2007), we describe the female labor supply effects, the distributional effects and costs to the government of changing transfer schemes. We discuss targeting versus universalism of family support schemes by two counterfactual simulations: the introduction of income testing in Norway and a universal design in Australia, which means that an income-tested child benefit schedule is introduced in Norway, whereas income tests are removed from the Australian Family Tax Benefit payments and childcare support 
schedules. Further, we show the effects of a move towards lower fees for care in childcare centers in Norway and Australia. Subsidization of childcare is a key family policy design issue in many countries.

Datta Gupta et al. (2008) discuss correlations of Nordic family policies with aggregate fertility, children's well-being and female employment, whereas the focus here is on the detailed effects of Nordic style family policies on individual labor supply and childcare use within a microsimulation context, controlling for other differences between Norway and Australia. The advantage of using a microsimulation approach instead of other microeconometric approaches is that hypothetical counterfactuals can be computed. ${ }^{1}$ That is, we can make hypothetical changes to the tax and transfer system in Norway and Australia, and then compute the expected effects on labor supply, government revenue and income distribution. Dearing et al. (2007) is an example of a study employing two separate microsimulation models to discuss the relationship between tax-benefit schedules designs and labor supply effects across countries, whereas Haan and Wrohlich (2007) discuss family policy design using microsimulation, specifying a welfare function, inspired by the approach taken in Saez (2002). In contrast to Haan and Wrohlich, the present approach does not evaluate policies based on an explicit social welfare function, but generates information about effects on social welfare indicators, such as labor supply and income distribution. To identify effects of policy changes in the two countries we need to control for differences in preferences, choice set constraints, and other institutional features of the two countries, which require country-specific microsimulation tools. The present paper includes descriptions of the two structural discrete choice labor supply models that are used (see Section 4 and the appendices).

By focusing on results from policy changes in two different countries, we highlight that family policy designs cannot be understood in isolation to the economic environment they are set to operate within. It is therefore important to situate the policies of interest in the economic and institutional frameworks of Norway and Australia. There are many similarities between Australia and Norway. Both countries are rich in natural resources and have managed to develop relatively ambitious welfare states along with upholding substantial economic growth. However, the objectives of family policies are fundamentally different in the two countries. Australian family policies are primarily designed to redistribute income

\footnotetext{
${ }^{1}$ A disadvantage of using microsimulation is that it is a partial equilibrium approach which does not account for the potential effect of policy changes on other parts of the economy. For example, labor demand is not taken into account.
} 
between families through income testing of transfers, whereas the Norwegian approach is to facilitate both parents to participate in the labor market by providing subsidized childcare and to provide equal income support to all families through an universal child benefit schedule. There are reasons to associate the vastly different labor supply of mothers in the two countries to this difference: a large proportion of Norwegian mothers participate in market work, whereas in Australia, mothers are much more inclined to be a homemaker. Thus, the potential for increased labor supply of mothers is large in Australia. However, the benefit of changing family policies in order to provide better labor supply incentives must be balanced against increased government expenditure and adverse effects on the distribution of income. Thus, there is no obvious conclusion that Australia should copy the "Nordic-style" of family policies; particularly given the fact that over the past two decades an increase in the labor supply of Australian mothers can be observed even without strong policy incentives. This is not to say that governments should not facilitate or even encourage this "natural" increase in labor force participation by supporting families who need to make additional costs to be in the labor force, but this must be gauged against other policy objectives.

In addition to effects on income distribution and labor supply incentives, family policies are concerned with other important issues, such as quality of care. Therefore, in Section 2, we first provide a brief introduction to economic motivations of family transfers. In Section 3 we describe features of the Australian and Norwegian economies. This constitutes the background for the discussion of the policy changes and assists the interpretation of results. It includes descriptions of children-related transfer programs, labor market participation rates and income distributions. Section 4 discusses the labor supply model used in the behavioral microsimulation. The labor supply effects and distributional effects from the microsimulations of the two proposed policy changes are presented in Section 5. Section 6 discusses the results and concludes the paper.

\section{The economics of transfers to families with children}

From an economic point of view, family transfers can be justified by the argument that parents with preschool children do not only face disincentives to work through direct taxation of their incomes, but must also take into consideration that market work for both parents implies additional expenditure in terms of childcare costs. It can then be shown that public provision of private services, such as childcare, can improve efficiency, because it alleviates the self-selection of high-income households making use of those services (Blomquist and Christiansen 1995). In line with this, Håkonsen (2003) denotes specialization gains in non- 
parental care, since the labor requirement per child is lower in centers compared to most families, and the efficiency gains by intervention through subsidized care come from the disincentives already created by the tax system. His calculations (for Norway) indicate that the optimal subsidy level is quite high; around 60 percent of gross costs of the services. As a counter argument, Rosen (1996) suggests that too many subsidies lead to excessive consumption of (tax-financed) care, which results in too much employment in care sectors and too little work in material goods sectors, resulting in what Rosen characterized as crosshauling; that is, women working for each other.

Another economic argument for intervention, noted by Jaumotte (2003), is excessively compressed wage distributions. Under such circumstances, the wages of carers (although usually at the low end of the distribution) may be too high compared to the wages of mothers. A third argument is that credit market restrictions may prevent low-income families to finance childcare and to get out of welfare dependency (Walker, 1996). Further, Bergstrøm and Blomquist (1996) argue that taxpayers without children may also vote for publicly provided childcare to increase labor supply for families with preschoolers and thereby reduce tax burdens, suggesting that there might be substantial Laffer-type revenue counteracting effects from subsidizing childcare. Graafland (2000) does not rule out such effects, as government deficits are approximately unchanged by increased expenditures on subsidies, when using a general equilibrium framework (the Dutch model MIMIC). Increased subsidies reduce wages and increase human capital investments and employment.

As noted in the introduction, transfers to families with children also serve other purposes, such as income support for the poor, highlighted by the EITC in the US and the WFTC in the UK. Although these two schemes do not only provide transfers to families with children, they tend to target this latter group and families with children tend to receive larger amounts. The two schemes originate from efforts to make low-income (working) families better off, ${ }^{2}$ and aim at providing support for these families without introducing adverse work incentives. Thus, in the UK-system a family needs to contain an adult who works 16 or more hours per week in order to be eligible, and then the credit is phased out with respect to income. Formal childcare costs are deductible up to 70 percent and the total deductible amount is limited by thresholds. According to Brewer et al. (2006), the largest effect of this tax credit scheme is found on lone parents' labor supply, whereas effects on couples are much less pronounced, partly because of counteracting effects on mothers and fathers. The EITC

\footnotetext{
${ }^{2}$ According to Hotz and Scholz (2003), the EITC started as a universal anti-poverty program.
} 
provides labor supply incentives by phasing the tax credit in (with respect to income) up to a maximum credit amount, and then phasing the credit out again with further increasing income. Hotz and Scholz (2003) report favorable effects of this scheme, with its ability to combine desirable labor supply effects and support for the working poor.

However, Kaplow (2007) argues that the family transfer issue should be discussed within an explicit optimal transfer perspective, for instance taking into account that changes in transfers often have revenue effects that have implications for taxation of the rest of the population. For instance, he finds support for high marginal tax rates on the working poor rather than subsidizing work. In other words, work subsidies are often inefficient tools to raise incomes of families at the low end of the income distribution. As noted by Acs and Toder (2007), this conclusion may not hold if individuals choose between jobs with fixed working hours and are not able to choose working hours along a continuous scale. A work subsidy may be optimal if the behavioral responses are concentrated on the extensive margin (the participation decision), as noted by Diamond (1980) and Saez (2002).

The optimal tax literature has also addressed the targeting versus universalism issue that we discuss in the present paper; see for example Immonen et al. (1998). They argue that an optimal scheme involves marginal tax rates that decrease in income within the richer group (families without children in our case), whereas marginal tax rates should increase in income among families with children, while at the same time providing a universal subsidy to this latter group, financed by increasing marginal tax rates over much of the income range. However, Creedy (1998) provides numerical examples and Kornstad and Thoresen (2004) present results from microsimulations which emphasize that income testing has detrimental labor supply effects that may outweigh distributional gains from greater targeting of support to families with children.

A government's intervening behavior should also take into account care quality differences between parental and non-parental care, if there are any. The child development literature often refers to cognitive and emotional competence of the child. Results indicate that the effect of a mother's entry into the labor market (and thereby non-maternal care) depends on the age of the child. Negative consequences are often found for cognitive ability when mothers enter market work while the child is still an infant, whereas results for older children (between one and two years of age) of working mothers are mixed (Averett et al., 2005). A UK study by Gregg et al. (2005) into the effect of a mother's employment on the cognitive outcomes of her children in early to mid childhood finds that only full-time employment in the first 18 months of her child's life has a negative effect. This is more so for 
higher educated women and less so for single women. The effect also depends on the type of non-parental childcare used. The negative effect is only evident when care consists largely of unpaid care by a relative, friend or neighbor. Furthermore, the results indicate that employment in combination with using center-based childcare may even have a positive effect on child development. These results are in line with evidence reported by Gregg et al. from US studies, where a return to full-time employment in the first year is also found to have some negative effect, but later returns to employment or part-time employment appear to have no effect. For instance, Berger et al. (2005) found, using US data, that a return to work within 12 weeks of giving birth negatively affects child development and health, particularly if the return is full-time.

Related research for Denmark by Datta Gupta and Simonsen (2007) found that, on average, participation in non-parental care has no effect compared to home care. However, the results diverge by type of non-parental care. Preschool, which employs highly qualified staff and more male staff, is found to be as good as home care. Family day care, however, seems to reduce non-cognitive skills for boys born to mothers with low levels of education. The intensity of non-parental care use is also important with increases in hours of use above the mean of 30 hours deteriorating child outcomes.

\section{Comparisons between Australia and Norway}

There are many similarities between Australia and Norway; both countries being rich in natural resources, possessing relatively ambitious welfare states, and belonging to highgrowth economies over the last decades (Mehlum et al., 2006). The two countries usually have high scores on many socio-economic indicators, which mean that they are often found among the highest ranked countries according to various indices, such as the Human Development Index from the United Nations. For instance, they have high scores on GDP per capita measures: measured in US dollars and adjusted with respect to purchasing power parities, gross national income per capita was 29,243 in Australia and 37,331 in Norway in 2003 (OECD 2006a).

However, the two countries differ substantially with regard to the design and generosity of family support schemes. In Jaumotte (2003), who describes family policies in OECD countries, Norway and Australia are often found on opposite ends of the scales of a variety of measures. In this section, we provide descriptions of family support transfer schemes in Section 3.1, families' labor supply in Section 3.2 and income distributions in the two countries in Section 3.3. More detail is available in Kalb and Thoresen (2007). 


\subsection{Family support transfers}

We compare various components of family support schemes, focusing on transfers directed towards families with children and dividing them into three subgroups: parental leave schemes, cash transfers/tax deductions, and childcare subsidies. We focus on general family policy tools, aimed at two-parent families. Education systems are not part of this study.

Norway and Australia represent the polar opposites of family support schemes: the Nordic model of subsidized non-parental care and universal family income support versus a support scheme based on means-tested or income-tested transfers. ${ }^{3}$

Nevertheless, fertility rates in Australia and Norway are rather similar. In 2006, it was 1.81 for Australia (Australian Bureau of Statistics (ABS), 2007) and 1.90 for Norway (Statistics Norway, 2007a), whereas parental leave schemes are rather different. In Norway, families with both parents in paid employment prior to birth can choose between full compensation over a period of 44 weeks and 80 percent compensation over 54 weeks. Mothers without work experience prior to birth receive a cash transfer of NOK33,584 (2007 value). ${ }^{4}$ The total cost of the parental leave scheme was about NOK11 billion in 2007.

In Australia, entitlements at the federal level are much lower. In principle, there is no paid maternity leave, although several individual employers are now offering women (and sometimes men) different amounts of paid leave, but this is often linked to tenure and/or returning to work within a certain period. ${ }^{5}$ Parental leave provisions include up to 52 weeks of unpaid parental leave for parents to take on a shared basis to care for their newborn child or newly adopted child under the age of five years. After the leave, parents have the right to be returned to the position held immediately before the start of parental leave or an equivalent position. In addition, there is a one-off payment of AU\$4,133 per child paid at birth, costing the Government about 0.2 billion dollars in 2003/2004 (ABS, 2006).

Obviously, there are strong labor supply reducing effects for women in the first year of their child's life arising from the Norwegian system for parental leave, compared to the Australian system. However, it is worth noting that there is a need for a fine balance between providing incentives to mothers to participate in the paid labor force and allowing women sufficient time to recover from birth and give their babies a good start in life. As noted before, it is found that a quick return to employment negatively affects child development and health,

\footnotetext{
${ }^{3}$ A third type is the in-work benefit schedules present in the UK and in the US

${ }^{4}$ For an approximate exchange rate between the Australian and Norwegian currencies, use $1 \mathrm{AU} \$ \approx 5 \mathrm{NOK}$. In addition, with reference to exchange rates in June 2007: 1US\$ $\approx 6 \mathrm{NOK}$ and 1 AU $\$ \approx 0.85 \mathrm{US} \$$.

${ }^{5}$ In the latest Federal Budget (May 2009), a national paid parental leave scheme was announced to be introduced in 2011. This will provide paid parental leave at the minimum wage level for 18 weeks.
} 
particularly if the return is full time; see for example, Berger et al. (2005).

In almost all industrialized countries, some sort of cash support conditional on the presence of children in families exists. The main difference between Norway and Australia is that the Australian Family Tax Benefit is income tested partly on household income and partly on the primary carer's income. The Child Benefit schedule in Norway is paid to all mothers of children between 0 and 18 years of age. The total costs of the Child Benefit scheme exceeded NOK14.3 billion in 2007.

In 2006/2007, the first type of family payment in Australia, Family Tax Benefit part A, pays the maximum rate per child to all families with children on an annual income under $\$ 40,000$. Some payment can still be received by families on relatively high incomes, with the minimum rate still being fully paid to families on an income of at least AU\$88,620 per year. A second payment, Family Tax Benefit part B, is available to all single-earner families in Australia and only income tested on the income of the secondary earner. The total cost of the Family Tax Benefit payments was AU\$12.9 billion in 2003/2004.

In Norway, three types of care for preschool children can be distinguished: parents' own care and two types of non-parental care, consisting of center-based care and babysitters. The centers are financed through national level governmental subsidies, support from local governments and parental fees.

The waiting lists for access to subsidized center-based care were a main argument for the introduction of the Home Care Allowance. This scheme gives all parents of preschool children aged 1 or 2 a tax-free transfer in cash, depending only on utilization of public or private day care centers. The reform was introduced to make government transfers across different modes of care more equal. This allowance cost approximately NOK2 billion in 2007.

Introducing Home Care Allowance was controversial, because the transfer provides incentives to withdraw from the labor market and care for children at home (Kornstad and Thoresen, 2007). In response, the so-called “childcare compromise” was introduced in 2004. It implies increased efforts to abolish queues for center-based care and a substantial reduction in parental fees through introduction of maximum prices, applicable to all center-based care. The initial intention of the reform was to reduce fees to NOK1,750 per month (in terms of 2005 prices). In contrast, parents paid on average NOK2,800 per month before the reform, in centers run by local authorities. Fees in private centers are usually above that level. There is serious doubt that the intended level will be reached, and for 2007, the maximum fees were set at NOK2,330 per month. In most centers owned by local authorities there are discounts for siblings, up to 50 percent of the rate for the first child. Finally, there is an income deduction 
scheme for childcare expenses through the tax system. ${ }^{6}$

In 2007, the Norwegian government transferred approximately NOK13.7 billion to childcare centers. Costs of the various financial programs to increase the supply of centerbased care are not included in that measure. The attendance ratio for children aged 1-5 reached 80 percent in 2006 (Statistics Norway, 2007b). The current Norwegian government plans to introduce a guaranteed right for access to center-based care for every pre-school child once the full coverage level is reached.

In Australia, Child Care Benefit is available to parents who have non-parental care expenditures. There are different childcare subsidy rates, depending on the number and age of children, the parents' incomes and labor market status, the type of childcare that is used and the number of hours of childcare that is used. A (small) minimum amount of AU\$0.497 per hour (in 2006/2007) is payable to all childcare users, independent of household income. In 2005/2006 the Australian government spent about AU\$1.5 billion on the Child Care Benefit, slightly up from AU\$1.4 billion in 2003/2004 (see ABS, 2006).

A second source of assistance to parents who pay for childcare is the Child Care Tax Rebate. If a work/study test is passed and the family has received Child Care Benefit, any costs remaining after deducting the Child Care Benefit from childcare costs for approved care can be rebated at 30 percent up to a maximum amount of $A U \$ 4,211$ per child. There is no income test for this rebate. ${ }^{7}$

In 2006, an estimated 801,060 children in Australia, from all age groups, made use of childcare services, compared to about 577,500 children in 1999 (Department of Families, Community Services and Indigenous Affairs, 2005; Department of Education, Employment and Workplace Relations, 2008). ${ }^{8}$ Assuming childcare is used only by children aged between 0 and 12 years of age (including after and before school care), the percentage of children using care has increased from nearly 17 percent in 1999 to nearly 23 percent in 2006. ${ }^{9}$ Counting only the childcare provided to children before they start school, we estimate that about 26 to 31 per cent of all children attend childcare in 1999 (depending on whether we include 5 year olds in the population of preschool children or not) which increases to about 33 to 40 percent in $2006 .^{10}$

\footnotetext{
${ }^{6}$ Deductions for childcare expenses are limited by an upper threshold; in 2007, this was set at NOK25,000 for the first child, to which NOK5,000 is added for each additional child.

${ }^{7}$ In 2008, the rebate percentage increased to 50 percent and the rebatable amount increased to AU\$7,500.

${ }^{8}$ This may include some double counting, if children use more than one type of formal care.

${ }^{9}$ We use population totals for children aged 0 to 12 (ABS, 2009).

${ }^{10}$ Some children start school at age 5 and others start school at 6 . Therefore, in our calculations we use population totals for children aged 0 to 5 and children aged 0 to 4 respectively (ABS, 2009).
} 
Comparing the costs of transfers in relation to aggregate economic measures such as tax revenues and GDP, different results are found for Australia and Norway. Summing the total costs of the various transfer programs for families with dependent children, we find that the costs in Norway were approximately NOK43 billion. This was about 7.4 percent of the estimated tax revenue for mainland Norway in 2007, or about 2.7 percent of mainland GDP. The average expenditure per child under 18 years of age in the population is estimated at NOK39,716. Summing the costs of the Australian transfer programs for 2003/2004 results in a total cost of AU\$14.5 billion (excluding the Child Care Tax Rebate which was not introduced then). This was about 6.9 percent of Commonwealth tax revenue. ${ }^{11}$ Approximately 1.6 percent of GDP was used for family support, which comes down to approximately AU\$2,853 per child under 18 years of age, much less than in Norway.

\subsection{Parents' attachment to the labor market}

Mothers' participation in the labor market is strikingly different between the two countries, even though differences have decreased over recent years. For instance, Jaumotte (2003) compared female labor force participation in 1981 with that in 2001: Australia's participation rate of women aged between 25 and 54 increased from just over 50 percent to just over 70 percent, whereas this rate increased from just over 70 percent to just over 80 percent in Norway. OECD (2006b) reports a rate of 70.7 and 79.9 percent for Australia and Norway respectively in 2005.

The effect of children is much more pronounced in Australia. Figure 1 provides information on measures for partnered mothers' labor supply in Australia and Norway by age of the youngest child, and compares them to females without children in the same age group (20-45). It confirms that Norwegian mothers of preschool children ${ }^{12}$ have higher participation rates, work less often part-time and work on average more hours compared to Australian mothers. As soon as the youngest child starts school (represented by age group 5-9), participation increases substantially in Australia but also in Norway, so there remains a substantial difference between mothers in the two countries. In fact, Norwegian mothers with a youngest child between 5 and 9 years of age have very similar connections to market work as females without children, except for lower part-time ratios in the latter group.

\footnotetext{
11 The 2003/2004 tax revenue was AU\$209 billion (ABS, 2005).

${ }^{12}$ We restrict the comparison to families with children aged between 1 and 4, because Australian children usually enter school at the age of 5 and many Norwegian mothers of infants are on paid parental leave in the first year.
} 
Figure 1. Labor market connections for married/cohabiting men and women, aged 20 to 45 , by age of the youngest child

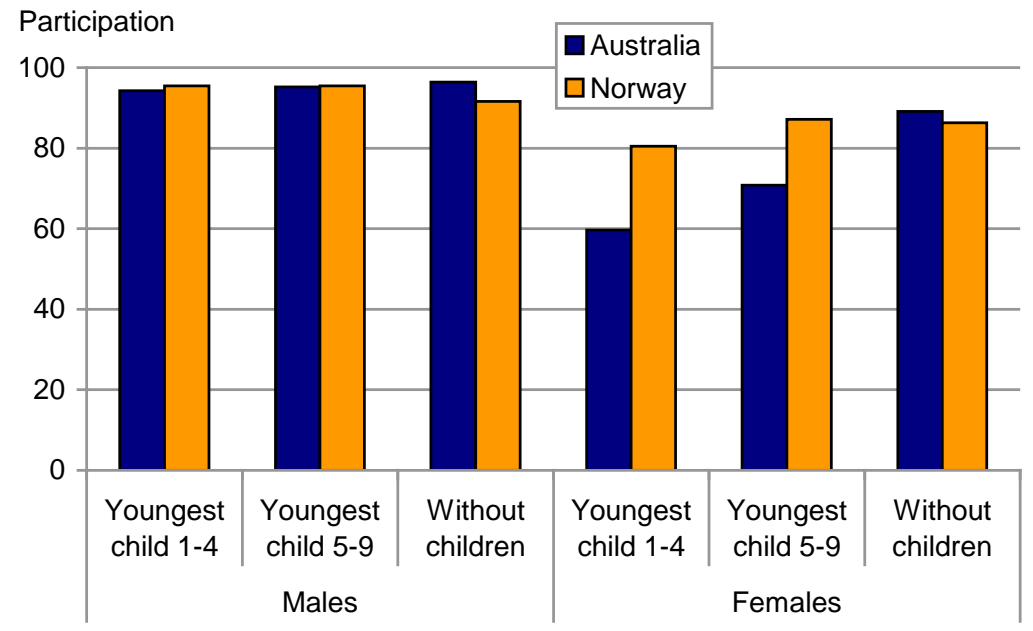

Part-time ratio

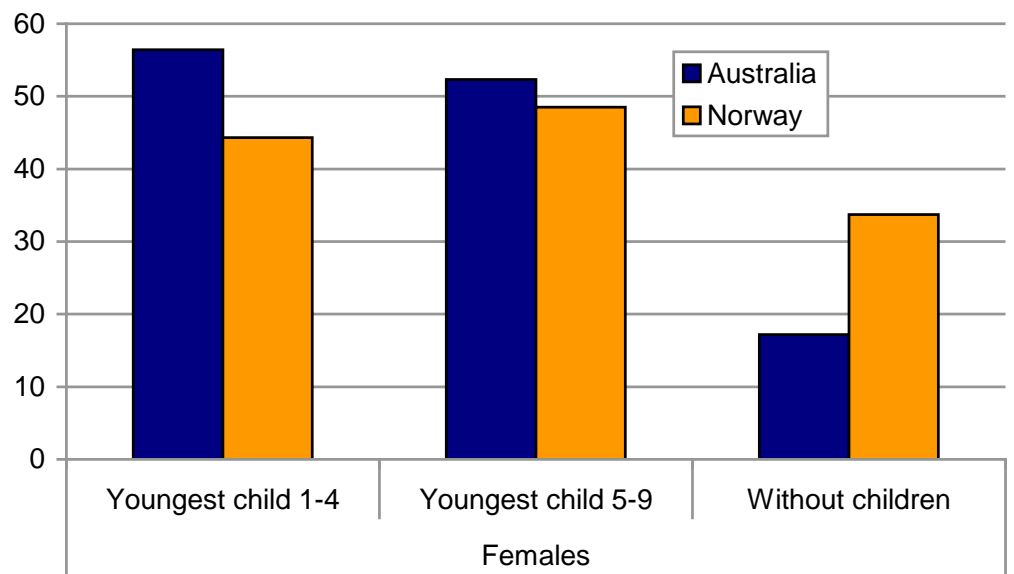

Average working hours

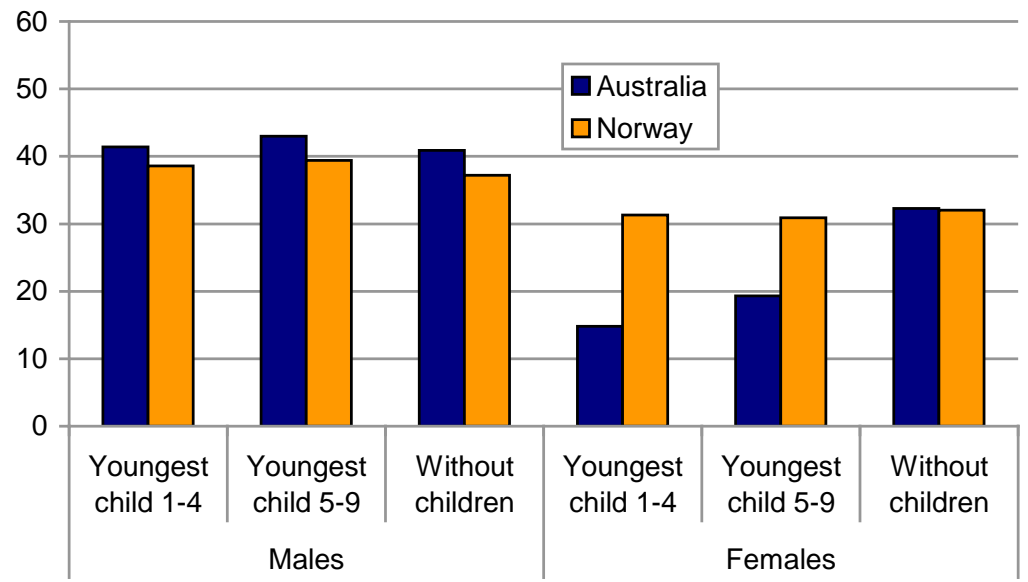

Sources: Authors' calculations using the Survey of Income and Housing Costs 2003/2004 for Australia and the Labour Force Survey 2005 for Norway.

Women without children, selected to be of a comparable age as the women with children in this figure, participate equally in the labor market in Australia and Norway. Australian and Norwegian fathers in the same 20-45 age group also follow similar patterns 
with respect to labor force participation and are hardly affected by the presence of young children.

\subsection{Income distributions}

Different redistributional objectives of family transfers, given the distribution of other income components, may contribute to the need for different transfer designs in Norway and Australia. Table 1 shows that although overall Australia is less equal, in accordance with previous findings for Norway and Australia (Gottschalk and Smeeding, 2000; Förster and Vleminckx, 2004), the subgroup of families with children has similar Gini coefficients in Norway and Australia. This similarity in income inequality seems mostly due to the targeted family payments in Australia. ${ }^{13}$ When family payments are excluded from post-tax income, the Gini coefficient increases substantially for Australia, indicating the importance of family payments for equality in Australia. Excluding the Child Benefit for Norway has a much smaller effect.

Table 1. Estimates of income inequality and the distribution of family transfers across incomes in 2007

\begin{tabular}{|c|c|c|c|c|}
\hline & \multicolumn{2}{|c|}{ Australia } & \multicolumn{2}{|c|}{ Norway } \\
\hline & $\begin{array}{c}\text { Gini } \\
\text { coefficient }\end{array}$ & $\begin{array}{c}\text { Concentration } \\
\text { coefficient }\end{array}$ & $\begin{array}{c}\text { Gini } \\
\text { coefficient }\end{array}$ & $\begin{array}{c}\text { Concentration } \\
\text { coefficient }\end{array}$ \\
\hline Income inequality & & & & \\
\hline All & 0.298 & & 0.268 & \\
\hline all families with children 0-17 & 0.247 & & 0.245 & \\
\hline same as above, excl. child benefit & 0.319 & & 0.262 & \\
\hline all families with preschoolers & 0.245 & & 0.245 & \\
\hline $\begin{array}{l}\text { Distribution of child benefit, all } \\
\text { families with children } 0-17\end{array}$ & & -0.340 & & -0.079 \\
\hline $\begin{array}{l}\text { Distribution of childcare subsidies, } \\
\text { all families with preschoolers }{ }^{\mathrm{a}}\end{array}$ & & -0.027 & & 0.440 \\
\hline
\end{tabular}

The concentration indices are as expected for the family payments in the two countries (negative for Australia and close to zero for Norway), given that Australia targets these payments at poorer households and Norway provides universal child benefits. The targeting of childcare subsidies in Australia is somewhat counterbalanced by the higher childcare use by

\footnotetext{
${ }^{13}$ Estimates presented in Table 1 are derived using the data sources of the microsimulation model for Norway and Australia; see descriptions of LOTTE (Norway) in Aasness et al. (2007) and of the Melbourne Institute Tax and Transfer Simulator (Australia) in Buddelmeyer et al. (2007). Income is measured by equivalent income, which is derived by aggregating income over all household members and divided by an equivalence scale to allow for economies of scale. The equivalence scale is defined as the square root of the number of household members, children included (Buhmann et al. 1988). Each household is represented with as many persons as there are household members.
} 
parents who are in the labor force (and therefore better off), resulting in a concentration index close to zero. Norway does not target childcare subsidies and therefore only experiences the latter effect, causing the concentration coefficient to be positive and large.

\section{Behavioral labor supply models for families with children}

Doiron and Kalb (2005) and Kornstad and Thoresen (2007) present two labor supply models developed to analyze effects of policy changes for families with (preschool) children in a microsimulation setting for Australia and Norway, respectively. Section 4.1 first presents the main features the two models have in common, before turning to the differences between the models. Kalb and Thoresen (2009) provide a more extensive discussion of model characteristics in relation to the literature in this area. Country differences are discussed in Section 4.2.

\subsection{Features of the Australian and Norwegian models}

The literature on the simultaneous choice of labor supply and childcare departs from the premise that market work by both parents typically implies demand for non-parental care, which entails (pecuniary) costs and may affect the wellbeing of children. In order to simulate effects of changes in childcare prices, taxes and other policy variables, it is particularly convenient to model choices as an outcome of preference maximization with respect to different constraints, such as time and budget constraints. This approach is followed for Norway and Australia. Both simulation models are based on structural discrete choice models. The models are estimated based on micro data information on families' decisions with respect to the parents' labor supply and the choices of care, and next the estimated model is used to simulate the behavioral responses to policy changes. The focus is predominantly on mothers' labor supply as they are considered to be the primary caregiver. ${ }^{14}$ However, the Australian model is a model for couples, predicting labor supply effects for both parents. Given the methodological challenges one faces when modeling joint labor supply and childcare decisions, and the different institutional settings in the two countries, the Australian and Norwegian models imply compromises along different dimensions of the complex choice situations. The aspects in which the two models differ are explained briefly below.

Complex budget constraints have motivated scholars to model labor supply as a discrete choice, where utility-maximizing individuals choose between a limited number of hours levels; see for instance Van Soest (1995), Aaberge et al. (1995), Dagsvik and Strøm

\footnotetext{
${ }^{14}$ The Norwegian sample consists of couple families in which the male partner works full-time.
} 
(2006) and the review by Creedy and Kalb (2005). Examples of structural discrete choice models for joint labor supply and childcare choices are Ribar (1995) and Brink et al. (2007); see also Blau and Hagy (1998), Michalopoulos and Robins (2000) and Powell (2002) for discrete choice models in joint childcare and labor supply decision frameworks.

Both models are based on a discrete choice approach: the Australian model is based on the approach of Van Soest (1995), whereas the Norwegian model is based on Kornstad and Thoresen (2007). The latter model extends the approach taken by Aaberge et al. (1995) and Dagsvik and Strøm (2006). The modeling framework of Van Soest (1995) only differs from a standard labor supply approach in that the set of feasible hours of work is finite, a feature that accommodates the formulation of a discrete choice model, which is convenient for empirical analysis and policy simulations. In contrast, the modeling approach of Kornstad and Thoresen (2007) departs from the assumption that the agent (family) chooses from a latent choice set consisting of combinations of childcare and job opportunities with alternative-specific attributes. Specifically, hours of work in a given job are assumed to be fixed. Thus, in this approach the agent's realized hours of work are the hours associated with the chosen job and care alternative. This point of departure yields a framework that is convenient for taking into account restrictions on hours of work, childcare and job opportunities, even though some of these restrictions are not observed by the researcher. For example, some families have no access to center-based care because of queues, and there are more full-time than part-time options available both with respect to jobs and childcare. ${ }^{15}$

Thus, Norwegian families are assumed to choose among job and care alternatives, given that they derive utility from consumption $(C)$, leisure of the mother $(L)$ and childcare quality $(Q)$. $B$ denotes the set of available jobs and $S$ the set of available childcare alternatives, where $k=1,2, \ldots$, represent job alternatives and $r=1,2, \ldots$, represent the care alternatives. $C_{k r}$ is the consumption/disposable income corresponding to job $k$ and childcare arrangement $r$. Its value is determined by annual hours of work in job $k$ for the mother, $H_{k}$, and the mother's wage income (the job-specific wage rate, $w_{k}$, multiplied by working hours), family income other than mothers' earnings $(I)$, costs of childcare $\left(M_{r}\right)$ and taxes $(\tau)$, leading to the following budget constraint:

$$
C_{k r}=w_{k} H_{k}+I-M_{r}-\tau\left(w_{k} H_{k}, I, M_{r}\right) \text {. }
$$

Under additional assumptions about the representation of preferences, a convenient

\footnotetext{
${ }^{15}$ Several contributions handle quantity constraints in the labor supply literature; see for instance Kapteyn et al. (1990), Ilmakunnas and Pudney (1990) and Dickens and Lundberg (1993),
} 
model can be derived that has a structure analogous to a multinomial logit model. See Appendix A for a summary of the assumptions and derivation of the empirical model.

A "fixed link" is assumed between hours of paid work by the mother and hours in care. However, stay-at-home mothers may also use non-parental care alternatives, in which case non-parental care is seen as contributing to childcare quality and not only as a means of alternative supervision, or alternatively, that stay-at-home mothers wish to give priority to other "home activities" or consume "real" leisure. "Leisure" is otherwise assumed to contribute to the well-being of preschoolers since mothers typically spend their time with children when not in paid work.

The deterministic part of the utility function is based on a "Box-Cox" utility function without explicit representation of childcare quality, except that mothers' "leisure" can be considered as contributing positively to care quality. It is difficult to find good representations for both parental and non-parental care quality. However, given that the model includes variables allowing for differences in opportunities across states, these variables may represent perceived (systematic) quality differences implicitly.

The care price measures are derived from external sources, whereas the individualspecific wage is based on a wage regression, where the unobserved heterogeneity, represented by the error term in the wage regression, is allowed for by averaging over 30 random draws from the log-normal distribution.

Whereas the Norwegian model does not include informal care alternatives, the Australian approach (Doiron and Kalb, 2005) highlights the choice between two modes of care, formal and informal care. The Australian model belongs to the family of discrete labor supply models that focus on heterogeneity in preferences, similar to Van Soest (1995), rather than characteristics of the alternatives, as in Kornstad and Thoresen (2007).

The Australian framework is based on a unitary household utility, similar to Brink et al. (2007), assuming that couple families maximize one utility function, a quadratic utility function in this case, subject to a time constraint for each adult $l_{i}+h_{i}=T$ and a standard household budget constraint:

$$
\begin{aligned}
& C_{h_{1} h_{2}}=w_{1} h_{1}+w_{2} h_{2}+y_{1}+y_{2}+B\left(h c, w_{1} h_{1}+w_{2} h_{2}+y_{1}+y_{2}\right)- \\
& \tau\left(B, w_{1} h_{1}+y_{1}, w_{2} h_{2}+y_{2}, h c\right)-c c\left(h_{1}, h_{2}, h c, w_{1} h_{1}+w_{2} h_{2}+y_{1}+y_{2}\right)
\end{aligned}
$$

where $l_{i}(\mathrm{i}=1,2)$ indicate the leisure hours (including home production) of the husband and wife (married or de facto) respectively; $h_{1}$ and $h_{2}$ are the hours of work of husband and wife; $T$ is the total time available for husband and wife; $C$ indicates net income (assumed to be equal 
to household consumption); $w_{1}$ and $w_{2}$ are the gross wage rates of husband and wife; $y_{1}$ and $y_{2}$ are the non-labor incomes of husband and wife; $h c$ is a set of household attributes; $B($.$) is the$ amount of benefit a household is eligible for given their household characteristics $h c$ and household income; $\tau$ is the tax function that indicates the amount of tax to be paid; and $c c$ is the childcare cost to be paid.

Rather than associating each household with one specific predicted childcare cost amount $c c$ in the labor supply model, recognizing the uncertainty in predicted childcare costs, repeated draws from the joint distribution of formal childcare hours (multiplied by the relevant fees) and informal childcare costs are taken by adding draws from the distribution of the error terms (the individual-specific random variations) to the expected childcare costs (see Kalb and Lee, 2008). A simulated maximum likelihood approach is used to estimate the labor supply model's parameters conditional on these draws. An advantage is that the calculation of the Child Care Benefits is more accurate in this approach compared to using expected childcare costs, given that the subsidy payable for the average childcare cost is not the same as the average Child Care Benefits based on potential outcomes for childcare costs. The results presented in Section 5.2 are based on a model estimated using 10 draws.

In Section 5, these estimated models are used to simulate effects of policy reforms. As discussed by Creedy and Duncan (2002), alternative procedures exist to derive measures of effects of policy changes from simulation models based on discretized hours choices. A key issue is how to determine the individuals' labor supply choice under the base-line tax-benefit scheme and under an alternative scheme, when information is derived from a probability distribution. One alternative is to choose the hours level that results in the maximum probability. Another alternative is to establish a maximum utility rule based on draws of error terms added to the deterministic utility component.

Simulation results for Norway are obtained by applying state probability distributions directly (without draws of stochastic elements). For each family, the probability of choosing a particular combination of labor supply and childcare arrangement is predicted under various tax-benefit schemes as described in Appendix A. Using these probabilities, the mathematical expectation with respect to various variables such as disposable income, hours of work, hours in non-parental care and income tax can be calculated. Differences in mean expected values for these measures across households are reported.

Simulation results for Australia are obtained using a user-specified number of random draws (100 in our case) for the random component of utility. This is added to the deterministic component of utility, $v\left(C, h_{1}, h_{2}\right)$, which is obtained using the parameter estimates of the 
quadratic preference function (see Appendix B). Using the repeated draws, an empirical probability distribution for the hours of work can be constructed at the individual level and aggregated up to the population level. The probability distribution can then be used to obtain expected labor supply responses or changes in expenditure at the individual level which can then again be aggregated up to the population level.

Comparisons of microsimulation results to results from alternative approaches have been carried out to a limited extent since it is difficult to find data on appropriate policy changes that can be simulated ex ante and evaluated ex post using, for example, quasiexperimental approaches. Cai et al. (2008) is one example for the Australian microsimulation model, in which consistent results were found from an ex-ante microsimulation analysis and an ex-post difference-in-difference analysis of the same policy change. Similarly, the simulation results for the Norwegian home care allowance reform (see description in Section 3.1), reported in Kornstad and Thoresen (2007), are consistent with evidence from ex-post analysis.

\subsection{Country differences and the need for different models}

Compared to international estimates of labor supply elasticities with respect to childcare costs or prices, both Norway and Australia are at the lower end of the range; a survey of estimates can be found in Kalb (2009). As discussed in Section 4.1, although the models for Australia and Norway belong to the same part of the literature for simultaneous labor supply and childcare choices, there are a number of differences. The two models are designed to capture important characteristics of the two economies they are assumed to operate in. ${ }^{16}$

Even if identical models were used and similar estimated parameters of the utility functions were found (indicating identical preferences in the two countries), Norwegian and Australian families could be expected to behave differently for a number of reasons. The nonlinearity of models will yield diverging results for different countries, for instance generated by tax and transfer system differences that are included implicitly in the model ${ }^{17}$ and different labor force participation rates in the two countries. For instance, Blau and Kahn (2007) find declining female labor supply elasticities for the US between 1980 and 2000, which are likely to have been influenced by the higher participation rates developing over the same period.

\footnotetext{
${ }^{16}$ Differences in the type of information available in data for the two countries have also influenced the modeling approach.

${ }^{17}$ It is the gross wage rate that enters the model, but it is the net wage rate that affects labor supply. Gross and net wage are often related in a non-linear way. Therefore the tax and transfer system in place will affect labor supply elasticities.
} 
Ceteris paribus, high labor market participation in Norway (see Section 3.2) is expected to generate less elastic labor supply at the extensive margin.

Turning to country-specific features, it is argued that the Norwegian model would be misspecified without accounting for rationing, reflecting the considerable focus on availability constraints in many European studies; see Gustafsson and Stafford (1992), and Del Boca and Vuri (2007). The main lesson from the childcare literature is that families appear less responsive to costs when availability is restricted. Kornstad and Thoresen (2007) compare labor supply elasticities in a situation allowing some families to be restricted from access to center-based care and a situation that assumes there is no rationing, and find slightly smaller elasticities in the latter case. Of course, this result depends on the actual choice limitations and the relationship of childcare use and labor supply.

Similarly, the Australian model allows families to use informal care alternatives, such as care by grandparents, whereas these arrangements are ignored in the Norwegian case, see Kornstad and Thoresen (2006). The effect of these differences on the simulation results is unknown and is likely to depend on the importance of the feature in representing the actual situation in each country.

\section{Labor supply and distributional effects of changes in Norwegian and Australian family transfer programs}

In this section we discuss the effects of policy changes in Norwegian and Australian family policies. Predicted effects on labor supply and income distribution are obtained through a number of simulations of alternative family policies for Australia and Norway, employing the behavioral microsimulation models described in Section 4.1.

To address the targeting or universalism issue, we present results from two counterfactual simulations: replacing the universal child benefit schedule of Norway with an income-tested Australian-type schedule and abolishing income testing of the family support schemes in Australia. Next, we discuss the effects of increased subsidization of childcare in the two countries by presenting effects of the substantial fee reductions following the socalled "childcare compromise" in Norway and describe effects of a similar reduction in childcare fees in Australia.

\subsection{More labor supply incentives or more targeting for Norway?}

As noted in the discussion so far, the design of Norwegian support schemes can be characterized as encouraging female labor supply. Recently, female labor supply incentives were further improved by the introduction of the so-called "childcare compromise”. In the 
following, we focus on the effects of lowering fees for center-based care by describing the effects of the fee reductions introduced by the "childcare compromise”. To achieve improved distributional effects of Norwegian family policies, calls are frequently heard to direct more resources to the neediest families, that is, to means-test the child benefit. Therefore we discuss the effects of replacing the universal design of the Norwegian child benefit schedule by a schedule similar to the Australian family payments, income testing included.

\subsubsection{Introducing an income-tested child benefit schedule for Norway}

One way to assess the importance of universality of family policy designs in encouraging labor supply is to simulate the effect of introducing an income-tested schedule for Norway, replacing the Norwegian universal scheme by the Australian design (the Australian Family Tax Benefit Part A and Part B are described in Section 3.1).

Results before and after the policy change are presented in terms of probabilities for various combinations of labor supply and childcare, distinguishing between center-based care and other paid-care alternatives. As described in Section 4.1, the simulated probabilities are derived by calculating the average probability for each combination, based on the individual choice probabilities. Similarly, with respect to descriptions of effects on income distributions: measures of incomes are obtained by calculating average expected equivalized disposable income over each discrete state, before and after the policy reform.

The labor supply effects of this change for families with at least one preschool child are shown in Figure $2{ }^{18}$ The figure clearly shows how this change causes mothers to move from alternatives with high hours of work to alternatives with lower working hours and to home work. The same pattern is observed independent of whether families use center-based care or other paid care alternatives. On average, mothers of preschoolers reduce their weekly labor supply by 8.6 percent, from 25.6 hours per week to 23.4 hours per week, corresponding to a reduction of approximately 8,000 person-years.

The effects of introducing income testing on the income distribution are shown in Figure 3. The effects on incomes can be decomposed into two components: first, the reforms affect household incomes in a direct way, which refers to the effect on disposable income before behavioral adjustments. Second, the income testing affects mothers' behavior both with respect to labor supply and the choice of childcare alternatives. These two effects are added together to obtain the total effect on incomes. Figure 3 shows percentage gains across quintiles relative to income in baseline.

\footnotetext{
${ }^{18}$ This policy change will also affect families with older children who are eligible for child benefit, but here we focus on families with preschool children.
} 
Figure 2. Probabilities in base-line system compared to probabilities when the Norwegian universal child benefit schedule is replaced by an income-tested design

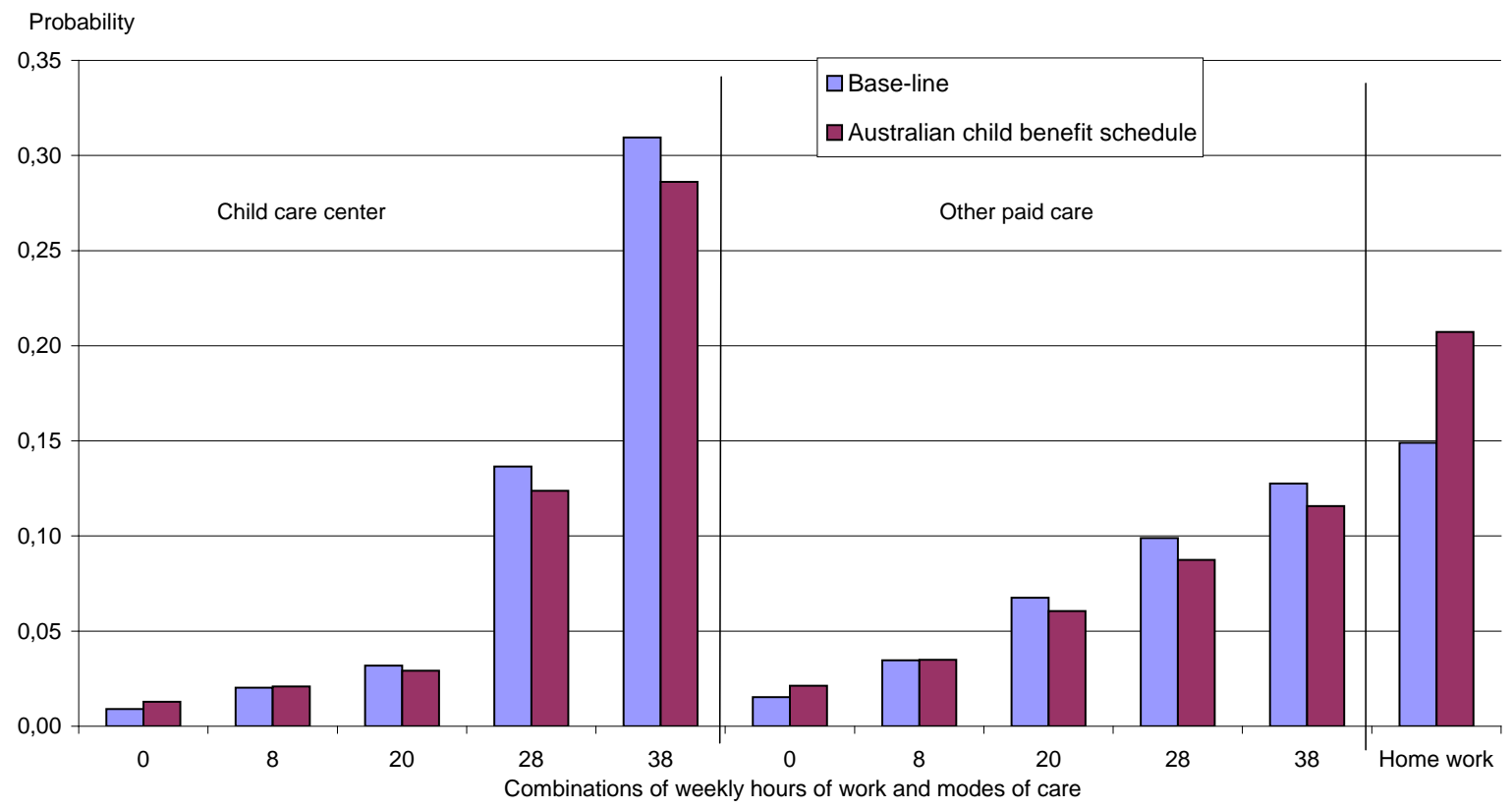

Figure 3. Effects on income distribution (in \%) and on weekly working hours (in average hours per week) from two policy changes, Norway.

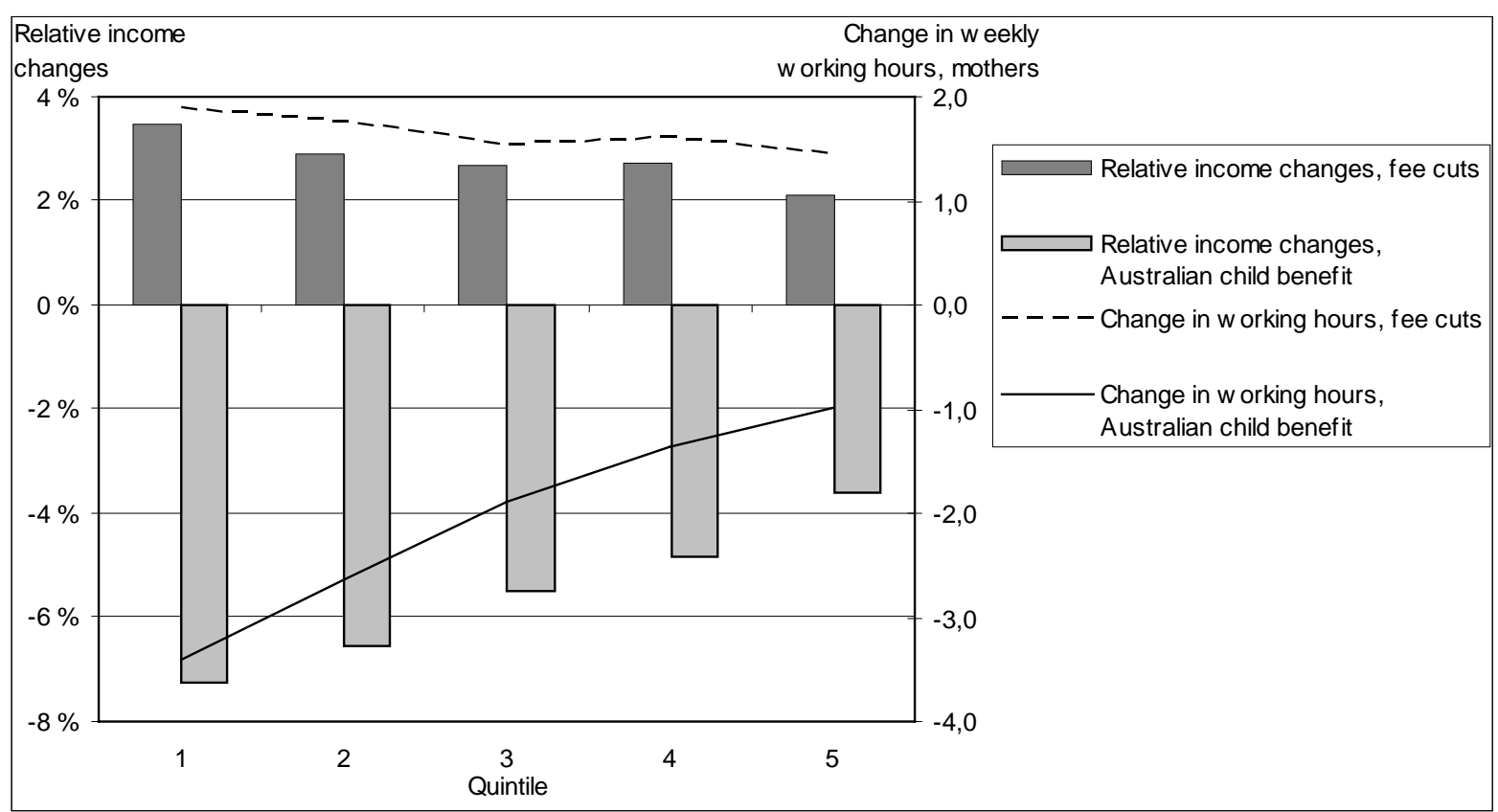

The absolute reductions in post-tax income are fairly similar across quintiles, which implies that the relative income reduction is larger for low-income households (see Figure 3). Low-income households are most responsive in terms of labor supply, implying that a substantial part of the income reductions at low levels of income stem from labor supply reductions, as was also observed in Kornstad and Thoresen (2004); the withdrawal of the 
transfer starts at fairly low income levels when translated into the Norwegian income distribution. Thus, introducing an Australian-type child benefit design would not only decrease mothers' labor supply, it would also result in a more unequal income distribution (among families with preschoolers). The change would reduce net government expenditure quite considerably: by about NOK6.2 billion, after taking the negative effects on tax revenue from lower labor supply reductions and the positive contribution from decreased childcare subsidies into account.

\subsubsection{Effects of a decrease in fees in center-based care in Norway}

As described in Section 3.1, the reform involves reducing fees for full-time care in day care centers to NOK1,750 per month (in 2005 prices). In contrast, parents paid NOK2,800 per month on average for full-time care in centers run by local authorities in August 2003 (Eibak, 2003). As there is doubt that the policy makers will reach the 1,750 level in the near future, we simulate effects of the fee reductions introduced so far, using the 2007 maximum fee of NOK2,330. ${ }^{19}$ Discounts for siblings and part-time care are taken into account.

The tax and transfer system for 2003 (just before the reform was introduced in 2004) serves as a reference or base-line when studying the effects. Thus, we project the data from the year of data collection, 1998, to 2003. The projection means that all income components, including female wage rates, are adjusted to 2003 levels by the wage growth in the period, that non-parental care prices are adjusted according to information on price changes in the period, and that families are taxed according to the 2003 tax law. The maximum fee in 2007 is deflated to the 2003 level of NOK2,150.

The reduction in prices is expected to increase demand for center-based care. Therefore, it might be unrealistic allowing mothers to choose freely under the prevailing conditions in the market for care at centers, even though the "childcare compromise" aims at ending waiting lists for center-based care. Under the assumption that the degree of rationing is at the same level as in the pre-reform system, we expect that the rate cuts will induce changes as described in Figure 4. The probability for parental care/home work decreases, and the use of full-time work/childcare center increases substantially. In total, the mother's labor supply increases by about two hours per week on average, or about 6 percent. This corresponds to an increase of about 5,600 person-years.

Figure 4 also shows the probabilities for an alternative simulation where the rate cut is combined with a no-rationing assumption, thus, simulating the total effect of the "childcare

\footnotetext{
${ }^{19}$ It appears that the policy makers have decided to end waiting lists first, before considering further fee reductions. The efficacy of this strategy is supported by new estimates of the costs of this reform.
} 
compromise". One may argue that this simulation provides a more realistic estimate of the effects, even though some families are still waiting for access. The behavioral effects are substantially stronger when removing the rationing constraint. For this alternative, the overall effect on hours of work is an increase in labor supply by about 11 percent, or approximately 10,300 person-years.

Figure 4. Probabilities in base-line system compared to probabilities when maximum fees at childcare centers are set at NOK2,150

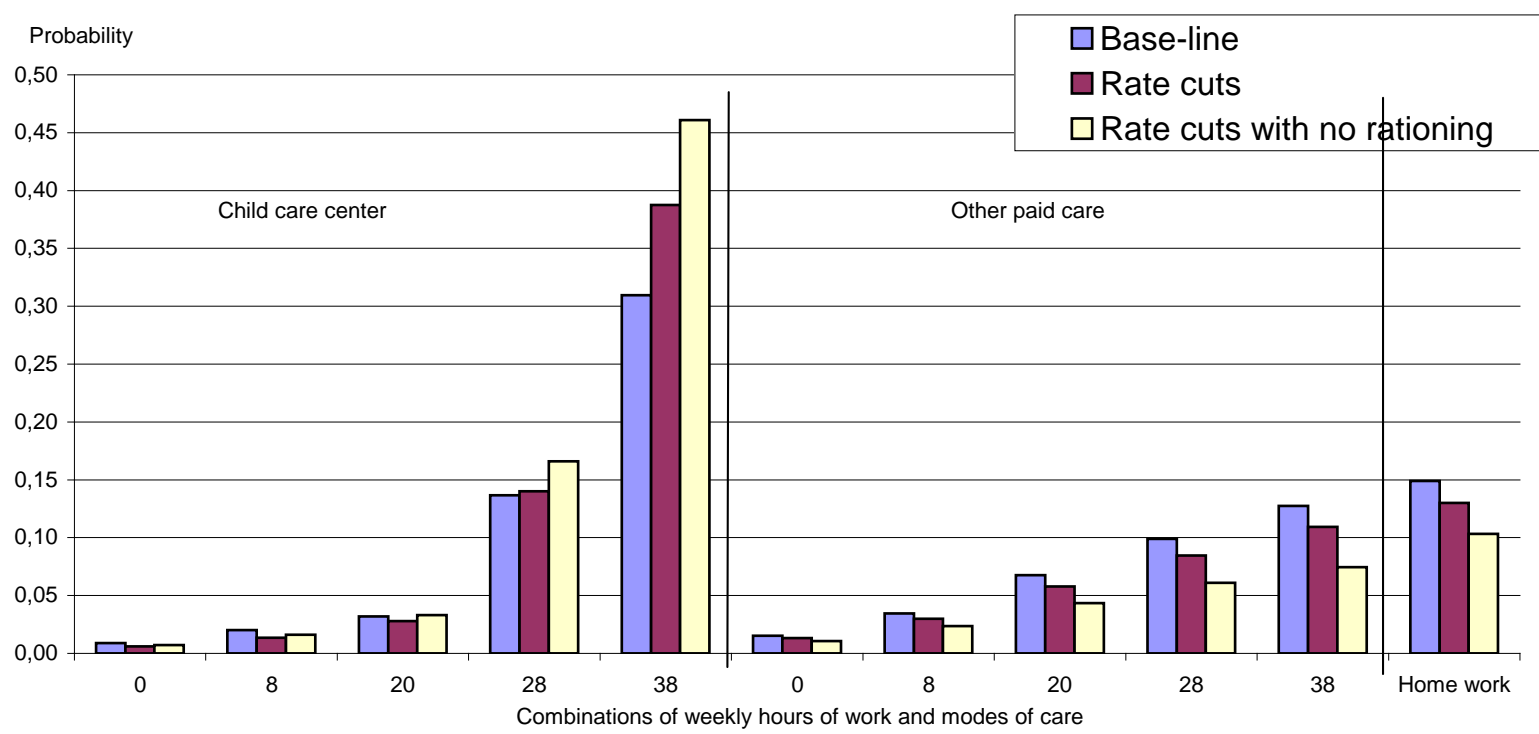

The effects of fee reductions on the income distribution in the case of unchanged rationing are shown in Figure 3. The distributional gains, as shown in Figure 3, reflect that the indirect effects through working hours responses and changes in the use of childcare centers are larger at the low end of the income distribution, while the direct effects are more significant among high-income families, as there is a positive relationship between income and use of center-based childcare in the pre-reform situation. Combining the two effects, benefits in absolute terms are larger for high-income quintiles compared to the other quintiles. Figure 3 shows percentage gains across quintiles relative to income in baseline. Although the relative gains are higher at the low end of the income distribution, the "childcare compromise" results in larger transfers (in absolute terms) to middle- and high-income households.

It has been difficult to predict the costs of this reform, partly because of its two-fold character, increasing availability and reducing prices at the same time. ${ }^{20}$ For example, the fee reductions have increased demand, resulting in increased waiting lists for an unaltered supply

\footnotetext{
${ }^{20}$ For instance, the official estimate of costs reported in Kornstad and Thoresen (2006) was too low.
} 
of the services. Using information from budget proposals, the increase in operational costs of the reform in 2007 (when maximum fees were reduced to NOK2,370) is estimated to be NOK 6.4 billion, including increased subsidies due to increased availability and to fee reductions. However, labor supply effects should be taken into account when calculating the budgetary costs. When deducting the tax revenue increase induced by the larger tax base following from increased female labor supply, approximately NOK1.3 billion $^{21}$ needs to be subtracted, resulting in an estimated total cost of NOK5.1 billion.

These simulation results clearly point out some of the dilemmas when designing family support schemes: the fee reductions encourage female labor supply, but they are not particularly focused on financial support for low-income families. That is, this example illustrates that there might be trade-offs between distributional ambitions and objectives to attract more women to market work.

\subsection{Does increased family support improve labor supply incentives in Australia?}

As discussed in Section 3.1, income testing is an important policy design issue where the two countries have chosen different directions: Norway provides universal payments to families and subsidizes childcare for all families who make use of it, whereas family payments and childcare subsidies in Australia are much more targeted at families at the lower end of the income range. Section 5.2.1 therefore discusses the effect of changing the 2002-03 family payments and childcare subsidies into universal payments ${ }^{22}$. In addition, we simulate the effect of a 50 percent decrease in formal childcare fees in Section 5.2.2, which is equivalent (percentage wise) to the intended fee reductions of the Norwegian reform (although, as discussed in Section 5.1.2, the fee reduction in Norway so far has been smaller).

\subsubsection{Abolishing all income tests in family payments and childcare subsidies}

In this section, we simulate the effect of having universal Family Tax Benefits and Child Care Benefits. The cost to the government of implementing this for the whole population (including sole parents), when labor supply effects are not taken into account, is AU\$9.504 billion in Family Tax Benefit payments and Rent Assistance. ${ }^{23}$ It is clear that if we do not want to reduce the support for low-income families and if we do not want to income test family payments, then the additional cost to government is going to be substantial.

\footnotetext{
${ }^{21}$ This estimate is derived from a simulation without availability restrictions and may somewhat overestimate the access to care in 2007, therefore representing a potentially upwardly biased estimate of the effect from an increased tax base.

22 The 2002-03 payments were very similar to the current situation, except for the Child Care Tax Rebate, which was introduced in 2004-05.

${ }^{23}$ To some extent, Rent Assistance is linked to receipt of the maximum rate of Family Tax Benefit.
} 
Using behavioral microsimulation, we can assess the effect of this policy on couples' labor supply. ${ }^{24}$ Women are shown to respond more than men to the reduced marginal effective tax rates resulting from abolishing all income tests associated with Family Tax Benefits and Child Care Benefits. Abolishing income testing on these payments would make it more attractive to enter the labor force by reducing the accumulation of withdrawal rates, which are added to the income tax, faced by this group. However, the effects are rather modest. Focusing on the same group as for Norway, including families with preschool children only, on average, mothers increase their average working hours by 0.86 hours (1.05 hours when selecting families with fathers who work at least 30 hours per week). This result reflects that the labor supply of Australian mothers is less elastic than the labor supply of Norwegian mothers. A smaller positive effect of 0.22 hours on average per week is found for men (-0.13 hours for full-time working men). Women are usually more responsive to financial incentives than men and they are also more likely to be currently out of the labor force.

For couple families, the total cost of the policy change is predicted to be AU\$9.247 billion of additional Family Tax Benefit payments and Rent Assistance and AU\$348 million in additional childcare subsidies. After taking into account everyone's labor supply responses, the overall cost to government decreases, since labor supply of partnered men and women are both expected to increase. Taking into account the additional income tax revenue and reduced income support payments, the cost to the government for introducing this policy change for couple families alone would be AU\$8.799 billion in additional income support, and an additional AU\$406 million in childcare subsidies. The latter have increased due to the expected increase in labor force participation which results in an increase in the use of childcare. The combined expenditures are thus only reduced with AU\$390 million due to increased labor supply.

Allowing for labor supply responses and focusing on couple families with preschool children and full-time working fathers only, Figure 5 shows that families in the higher quintiles receive on average a somewhat smaller increase in their equivalized disposable income than families in the middle quintiles. However, in absolute terms their increase would be highest. The lowest relative and absolute increase is observed for families in the lowest income quintile. However, this would have been even lower without labor supply changes. This is a result of the lower quintiles being more likely to change labor supply due to the

\footnotetext{
${ }^{24}$ The labor supply model only predicts the labor supply changes for wage and salary workers between 15 and 64 years of age. Those who are self-employed, full-time students or disabled remain at their observed labor supply in the simulation.
} 
policy change than the higher quintiles, thus benefiting more from the policy change than they would have without changing their labor supply. Similar to the results for Norway, Figure 5 shows that the direct effects of the policy change are lowest for the bottom quintile whereas the indirect effects (through changed labor supply) are higher for the lower quintiles, resulting in a combined effect which is largest for the middle quintile in relative terms and for the top quintile in absolute terms. Labor supply responses are lower in the higher quintiles than in the first two quintiles.

\section{Figure 5. Effects on income distribution and on weekly working hours from abolishing income testing in Australia ${ }^{a}$}

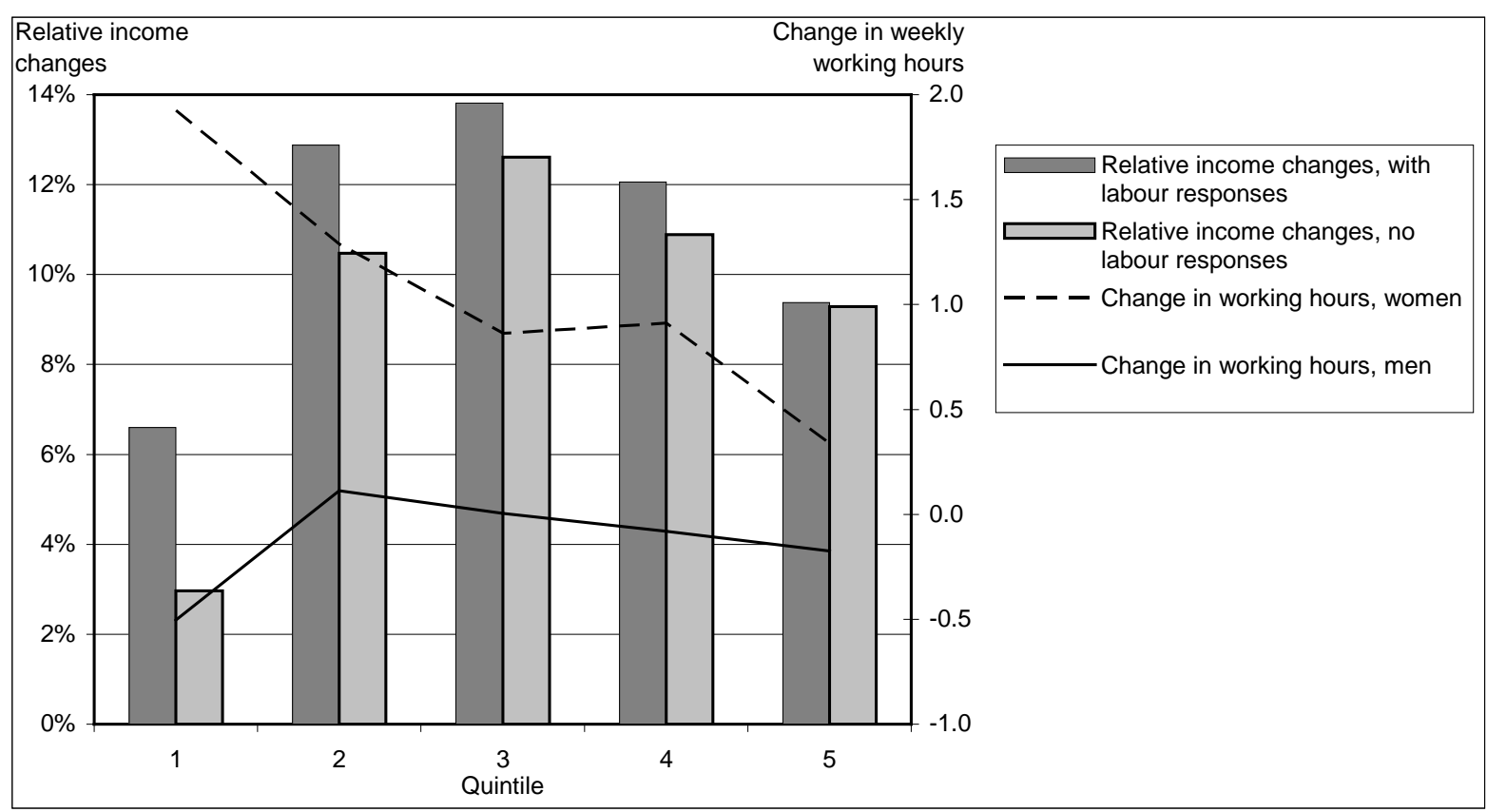

Note a: By quintiles of equivalized disposable income unit income.

\subsubsection{Decreasing childcare fees}

To create a comparable policy change to the Norwegian fee reductions, we simulate a reduction in childcare fees by 50 percent, which is comparable in relative terms to the reduction in Norway when the reform has been fully implemented. The main component of the costs to the government relates to halving childcare fees. This cost is calculated by taking 50 percent of the original childcare costs, assuming that childcare prices do not change as a result of this additional subsidy. For all families together the cost is estimated at AU\$0.9 billion per year, and for couple families only, the cost is estimated at AU\$0.7 billion per year. Due to the lower childcare fees, direct childcare subsidies to families also decrease (assuming that families would not receive more in subsidy than they pay for childcare services).

The labor supply responses are much lower than for the abolishment of income testing: an increase of 0.02 hour per week for men (-0.03 for full-time working fathers) and 
0.22 hour per week for women (0.28 for families with full-time working fathers), including only families with children aged under 5 years. The subsidy decreases by about AU\$49.4 million per year when taking everyone's labor supply into account (compared to a decrease of about AU\$60.5 under fixed labor supply). Additional tax revenue of AU\$49 million and reduced expenditure of AU\$48 million is expected due to increased labor supply. Overall, taking labor supply responses into account, government expenditure would be reduced by about AU\$86 million.

Comparing the average effect of the policy change by equivalized income quintiles for couple families with preschool children and full-time working fathers, Figure 6 shows clear differences between quintiles. Similar to the policy change in Section 5.2.1, although the change in income is much smaller, the direct effect is highest for the higher quintiles (both in absolute and relative terms). The indirect effect through labor supply is highest for women in the middle income quintiles. Combining the two effects, this policy change is likely to benefit the higher income quintiles more than the lower income quintiles.

Figure 6. Effects on income distribution ${ }^{\mathrm{a}}$ and on weekly working hours from childcare fee reductions, Australia

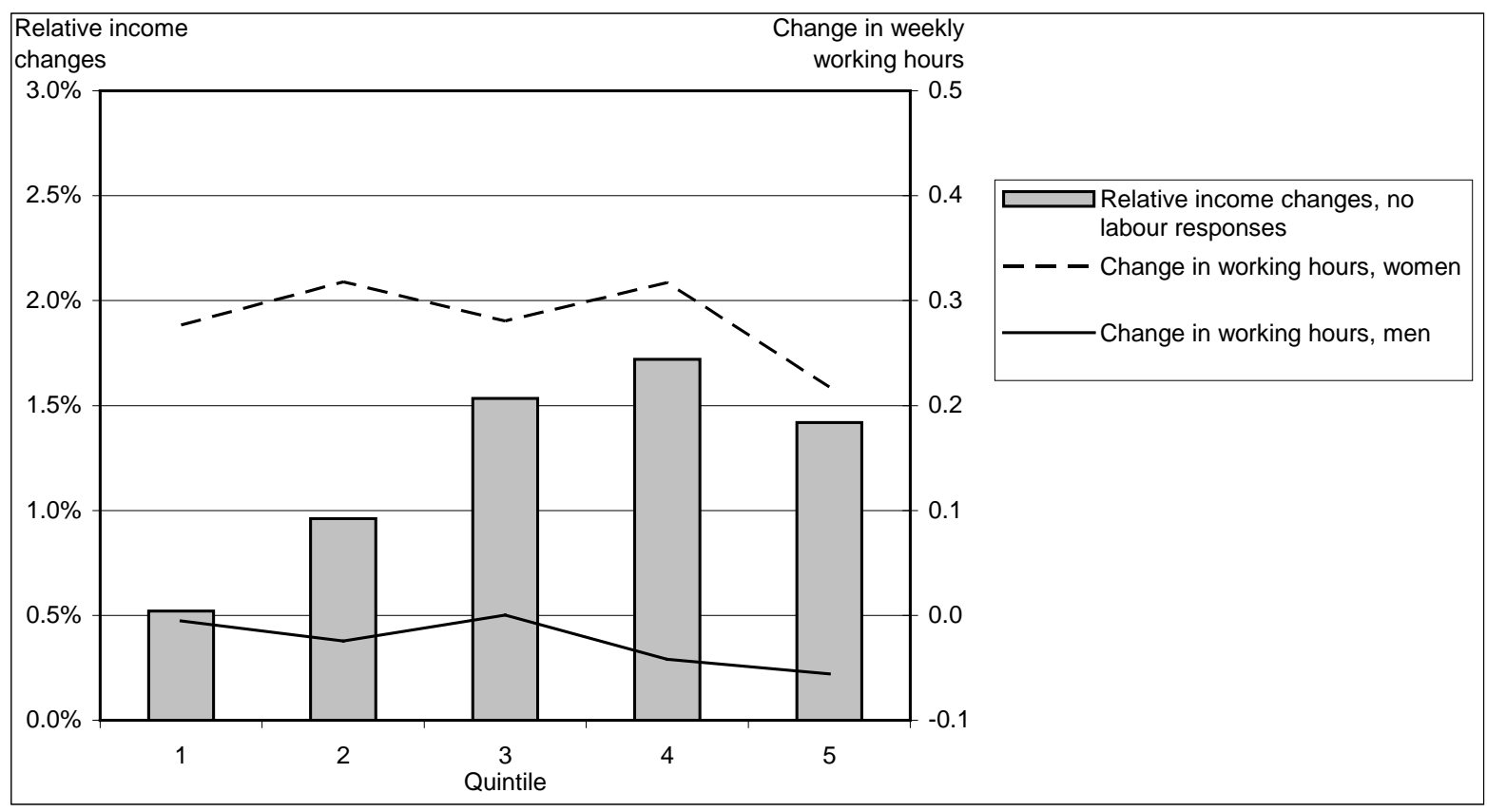

Note a: Changes in disposable income (net of childcare cost) are calculated at fixed labor supply levels. At the moment, the change in income when allowing for labor supply responses cannot be calculated for this simulation. However, given the small labor supply responses the results will be similar to the results assuming fixed labor supply.

\section{Discussion and conclusion}

The family policy models of Australia and Norway represent two alternatives to the "in-work" type family support systems of the UK and the US. Norwegian policy is based on subsidized 
non-parental care and universal family income support, whereas Australian support mostly consists of income-tested transfers. This paper has discussed these distinct differences between Australia and Norway with respect to family policies and the economic conditions they work within, using microsimulation models for Norway and Australia. Microsimulation is particularly useful in this context, since it allows the analysis of hypothetical policy changes on a range of social welfare indicators; here labor supply and income distribution are used.

We find close relationships between the two types of family policy designs and country characteristics, such as income distributions and female labor supply. From an income-redistributional perspective, Australian family policies play a major role in alleviating income dispersion, whereas Norwegian support schedules work in an economy which starts from a lower income inequality before family transfers. It is reasonable to hypothesize that low income inequality, before making any transfers, facilitates support schemes with weaker redistributional effects. For instance, with its universal design, the Norwegian Child Benefit does not redistribute to the same extent as the Australian Family Tax Benefit. Moreover, as shown, Norway is currently investing even more money in the childcare sector through childcare fee reductions. With their strong link to labor supply, these subsidies are not particularly pro-poor. The aim of ending waiting lists and moving towards making access to center-based care a legal right may indicate that recent family policy changes in Norway have been motivated by other equity concerns judged to be of more importance than the redistribution of income. For example, universal high-quality and affordable childcare may be considered to facilitate upward mobility for children from disadvantaged backgrounds by providing them with better opportunities.

Labor force participation rates of Australian mothers are substantially below the Norwegian levels, and part-time ratios are higher in Australia. Different designs of family policy schemes are likely to have contributed to this, even though the direction of causality is not obvious. For example, the income testing in Australia may have been developed as a result of few females participating in market work. Alternatively, the differences in family policy schemes and in female labor supply behavior could have arisen from underlying factors such as differences in cultural norms or gender equality preferences. Such factors are difficult to observe and measure.

The analysis shows effects on mothers' labor supply, on income distributions and on the costs to government of introducing family policy changes. Reduced childcare fees in Norway are shown to encourage female labor supply, but this labor supply stimulating policy change does not make Norway's income distribution more equal. That is, this simulation 
illustrates that there might be trade-offs between the aim of redistributing incomes and the objective to attract more women to market work. Since the amount of resources being transferred to families with children is already substantial in Norway, labor force participation of Norwegian parents is already high and the income redistributional performance of fee reductions is weak, there are reasons to question the introduction of further labor supply incentives, such as these fee reductions, with the associated further use of revenues for families with children. There appears to be relatively little gain at a rather high cost. However, this initiative could also be seen as an investment in education providing an additional or alternative justification for the expenditure. This justification is supported by the transfer of the responsibility for childcare policies from the Ministry of Children and Family Affairs to the Ministry of Education. As a result, the combination of low fees and close to 100 percent coverage for center-based care (at least for children aged between 3 and 5 years) could be interpreted as a move to include preschool care as part of publicly provided education in Norway. ${ }^{25}$ Although further childcare fee reductions or increased family benefits may not be recommended, simulations in Section 5.1.1 show that going towards an income-tested child benefit schedule (thus reducing expenditure on families) would have quite substantial negative effects on labor supply, particularly for lower income groups which would also be an undesirable result. Thus, the results presented here do not support the case for greater targeting of the Norwegian child benefit schedule; abolishing universalism comes at a cost.

The results for Australia support the same view as the results for Norway: labor supply encouraging policy changes are costly, have detrimental distributional effects and the gains in terms of working hours are limited. The main reason for effects not being stronger is that Australian mothers are not found to be very responsive with respect to changes in childcare costs. The abolition of all income testing on family payments and childcare subsidies is found to be very costly if we do not want to reduce the support for low-income families. Furthermore, a large proportion of the additional expenditures are transferred to families at the high end of the income range, similar to the Norwegian simulation.

The lack of substantial distributional gains from labor supply adjustments is also shown when simulating a reduction in the childcare fees in Australia. Even though labor supply responses are higher at low levels of income, the effects are too modest to have a substantial effect on income distributions. Again, the additional expenditure is expected to benefit mostly those at the higher end of the household income range.

\footnotetext{
${ }^{25}$ This reinforces the need for more information about social and cognitive outcomes of early education systems.
} 
Therefore, one may ask if the Nordic model is a system to which Australia should aspire. ${ }^{26}$ Given the evidence regarding a few aspects presented here, such as low elasticities and the limited changes in labor supply when simulating the effects of policy changes towards the Nordic system, the substantial increases in female labor supply without major interventions over the past decades, and given the inequality of pre-tax and transfer income, the continued use of family policies to redistribute income may be preferable over a more universal system in the Australian context. The argumentation of Kaplow (2007), regarding the effects of policies on government revenue and subsequent effects on income taxation (as discussed in Section 2), can also be interpreted in support of this view. Thus, even though Australian and Norwegian economies are similar in several ways, the evidence presented here does not provide strong support for a move towards the Norwegian system in Australia. It might cost too much in terms of higher taxes and less income redistribution relative to what it is expected to deliver in terms of labor supply.

Despite the expected lack of success of introducing a number of aspects of the Nordic style family income support there remains a concern in Australia regarding relatively low labor force participation rates of mothers. High and continually rising prices for non-parental care in Australia may prevent low-income mothers to participate in the labor market. It is suggested that more targeted rather than universal payments may be appropriate in the Australian context, in which there is more inequality in pre-tax incomes and in which most transfers are tightly targeted towards low-income households. Perhaps in-work benefits similar to those in the US and UK are worth considering as examples of labor supply incentives that fit within the Australian system by specifically targeting low-income households (see Buddelmeyer et al., 2007). Alternatively, linking additional childcare subsidies to a certain level of participation in the labor force may achieve favorable results (see Kalb and Lee, 2007). These alternatives may achieve more additional labor supply per dollar spent (resulting in a lower cost to the government), by targeting those who are currently not working or working low hours, and may aid in achieving more equitable income distribution outcomes.

Finally, another aspect worth mentioning in relation to the Australian support system is compliance and administration costs. The income testing complicates the administration of income support payments requiring authorities to check incomes and assets of applicants,

\footnotetext{
${ }^{26}$ Datta Gupta et al. (2008) discuss the positive and negative impacts of Nordic countries' family-friendly policies on employment, wages, fertility, and children's well-being more generally (that is, without a focus on Australia).
} 
which is likely to generate substantial costs for the authorities to administer and for the taxpayers to comply with the rules. Ideally, such costs should be included when evaluating policies and policy changes, but may be difficult to quantify.

\section{Acknowledgments:}

This paper was written when the second author visited the Department of Economics and the Melbourne Institute of Applied Economic and Social Research at the University of Melbourne. Both institutions are gratefully acknowledged for their hospitality. A previous version of this paper was presented at the Australian Labour Market Research Workshop, 8-9 February 2007, and at the International Microsimulation Conference, 20-22 August 2007. We thank John Creedy, John K. Dagsvik, Prem Thapa and two anonymous referees for their comments on earlier versions of this paper and Tom Kornstad for assisting with the simulations for Norway. The first author also acknowledges the financial support of the Australian Research Council, which funded this research through a Discovery Project Grant (\# DP0770567).

\section{References}

Aaberge, R., J. K. Dagsvik and S. Strøm (1995). Labor Supply Responses and Welfare Effects of Tax Reforms. Scandinavian Journal of Economics, 97, 635-659.

Aasness, J., J. K. Dagsvik and T. O. Thoresen (2007). LOTTE - The Norwegian Tax-Benefit Model System. In A. Gupta and A. Harding (eds.), Modelling Our Future: Population Ageing, Health and Aged Care, International Symposia in Economic Theory and Econometrics Volume 16 (513-518). Amsterdam: Elsevier.

Acs, G. and E. Toder (2007). Should we Subsidize Work? Welfare Reform, the Earned Income Tax Credit and Optimal Transfers. International Tax and Public Finance, 14, 327-343.

Australian Bureau of Statistics (ABS) (2005). Taxation Revenue, Australia (reissue), 2003-04. Catalogue no. 5506.0, Canberra.

ABS (2006). Yearbook Australia, 2005. Catalogue no. 1301.0, Canberra.

ABS (2007). Births Australia, 2006. Catalogue no. 3301.0, Canberra.

ABS (2009). Population by Age and Sex, Australian States and Territories, Jun 2008. Catalogue No. 3201.0, Canberra.

Averett, S.L., L.A. Gennetian and H.E. Peters (2005). Paternal child care and children's development. Journal of Population Economics, 18, 391-414. 
Berger, L.M., J. Hill and J. Waldfogel (2005). Maternity Leave, Early Maternal Employment and Child Health and Development in the US. The Economic Journal, 115, F29-F47.

Bergstrøm, T. and S. Blomquist (1996). The Political Economy of Subsidized Day Care. European Journal of Political Economy, 12, 443-457.

Blau, D.M. and A.P. Hagy (1998). The Demand for Quality in Child Care. Journal of Political Economy, 106, 104-146.

Blau, F.D. and L.M. Kahn (2007). Changes in the Labor Supply Behavior of Married Women: 1980-2000. Journal of Labor Economics, 25, 393-438.

Blomquist, S. and V. Christiansen (1995). Public Provision of Private Goods as a Redistributive Device in an Optimum Income Tax Model. Scandinavian Journal of Economics, 97, 547-567.

Blundell, R., A. Duncan, J. McCrae and C. Meghir (2000). The Labour Market Impact of the Working Families’ Tax Credit. Fiscal Studies, 21, 75-104.

Brewer, M., A. Duncan, A. Shephard and M.J. Suárez (2006). Did Working Families’ Tax Credit Work? The Impact of In-work Support on Labour Supply in Great Britain. Labour Economics, 13, 699-720.

Brink, A., K. Nordblom and R. Wahlberg (2007). Maximum Fee vs. Child Benefit: A Welfare Analysis of Swedish Child-Care Fee Reform. International Tax and Public Finance, 14, 457-480.

Buddelmeyer, H., J. Creedy and G. Kalb (2007). Tax Policy Design and Behavioural Microsimulation Modelling. Cheltenham: Edward Elgar.

Buhmann, B., L. Rainwater, G. Schmaus and T.M. Smeeding (1988). Equivalence Scales, Well-being, Inequality, and Poverty: Sensitivity Estimates across Ten Countries Using the Luxembourg Income Study (LIS), database. Review of Income and Wealth, 34, 115-142.

Cai, L., G. Kalb, Y.P. Tseng and H. Vu (2008). The Effect of Financial Incentives on Labour Supply: Evidence for Sole Parents from Microsimulation and Quasi-Experimental Evaluation. Fiscal Studies, 29(2), 285-325.

Creedy, J. (1998). Means-Tested versus Universal Transfers: Alternative Models and Value Judgements. Manchester School of Economic and Social Studies, 66, 100-117.

Creedy, J. and A.S. Duncan (2002). Behavioural microsimulation with labour supply responses. Journal of Economic Surveys, 16, 1-39.

Creedy, J. and G. Kalb (2005). Discrete Hours Labour Supply Modelling: Specification, Estimation and Simulation. Journal of Economic Surveys, 19, 697-734.

Dagsvik, J. K. and S. Strøm (2006). Sectoral Labor Supply, Choice Restrictions and 
Functional Form. Journal of Applied Econometrics 21, 803-826.

Datta Gupta, N. and M. Simonsen (2007). Non-Cognitive Child Outcomes and Universal High Quality Child Care. Institute for the Study of Labor (IZA) Discussion Paper no. 3188, Bonn.

Datta Gupta, N., N. Smith and M. Verner (2008). The impact of Nordic countries' family friendly policies on employment, wages, and children. Review of Economics of the Household, 6, 65-89.

Dearing, H., H. Hofer, C. Lietz, R. Winter-Ebmer and K. Wrohlich (2007): Why are Mothers Working Longer Hours in Austria than in Germany? A Comparative Microsimulation Analysis, Fiscal Studies, 28, 463-495.

Del Boca, D. and D. Vuri (2007). The Mismatch between Employment and Child Care in Italy: the Impact of Rationing. Journal of Population Economics, 20, 805-832.

Department of Education, Employment and Workplace Relations (2008). 2006 Australian Government Census of Child Care Services: Summary Booklet. Commonwealth of Australia, Canberra.

Department of Families, Community Services and Indigenous Affairs (2005). 2004 Census of Child Care Services: Summary Booklet. Commonwealth of Australia, Canberra.

Diamond, P.A. (1980). Income Taxation with Fixed Hours of Work. Journal of Public Economics, 13, 101-110.

Dickens, W. and S.J. Lundberg (1993). Hours Restrictions and Labor Supply. International Economic Review, 34, 169-191.

Doiron D. and G. Kalb (2005). Demands for Childcare and Household Labour Supply in Australia. Economic Record, 81, 215-236.

Eibak, E.E. (2003). Undersøking om foreldrebetaling i barnehagar august 2003. Notater 2003/77, Statistics Norway. (in Norwegian)

Eissa, N. and H.W. Hoynes (2004). Taxes and the Labour Market Participation of Married Couples: The Earned Income Tax Credit. Journal of Public Economics, 88, 1931-58.

Förster, M.F. and K. Vleminckx (2004). International Comparisons of Income Inequality and Poverty: Findings from the Luxembourg Income Study. Socio-Economic Review, 2, 191212.

Gottschalk, P. and T.M. Smeeding (2000). Empirical Evidence on Income Inequality in Industrialized Countries. In A.B. Atkinson and F. Bourguignon (eds.), Handbook of Income Distribution, Vol. 1 (pp. 261-307). New York: Elsevier-North Holland.

Graafland, J.J. (2000). Childcare Subsidies, Labour Supply and Public Finance: An AGE 
Approach. Economic Modelling, 17, 209-246.

Gregg, P., E. Washbrook, C. Propper and S. Burgess (2005). The Effects of a Mother's Return to Work Decision on Child Development in the UK. The Economic Journal, 115, F48F80.

Gustafsson, S. and F. Stafford (1992). Child Care Subsidies and Labor Supply in Sweden. Journal of Human Resources, 27, 204-230.

Haan, P. and K. Wrohlich (2007): Optimal Taxation: the Design of Child-Related Cash- and In-Kind Benefits. Forthcoming German Economic Review.

Hotz, V.J. and J.K. Scholz (2003). The Earned Income Tax Credit. In R. Moffitt (ed.), MeansTested Transfer Programs in the United States (pp.141 - 198). Chicago and London: The University of Chicago Press.

Håkonsen, L. (2003). Child Care Subsidies and Economic Efficiency. Working Paper no. 17/2003, Telemark Research Institute.

Ilmakunnas, S. and S. Pudney (1990). A Model of Female Labour Supply in the Presence of Hours Restrictions. Journal of Public Economics, 41, 183-210.

Immonen, R., R. Kanbur, M. Keane and M. Tuomala (1998). Tagging and Taxing: The Optimal Use of Categorical and Income Information in Designing Tax/Transfer Schemes. Economica, 65, 179-192.

Jaumotte, F. (2003). Labour Force Participation of Women: Empirical Evidence on the Role of Policy and other Determinants in OECD Countries. OECD Economic Studies, No. 37, 2003/2.

Kalb, G. (2009). Children, Labour Supply and Childcare: Challenges for Empirical Analysis. Forthcoming in Australian Economic Review.

Kalb, G. and W.-S. Lee (2007). The Effect of an Alternative Childcare Subsidy on Labour Supply: A Policy Simulation. Australian Journal of Labour Economics, 10, 39-57.

Kalb, G. and W.-S. Lee (2008). Childcare Use and Parents' Labour Supply in Australia. Australian Economic Papers, 47, 272-295.

Kalb, G. and T.O. Thoresen (2007). The Case for Labour Supply Incentives: A Comparison of Family Policies in Australia and Norway. Melbourne Institute of Applied Economic and Social Research Working Paper No. 27/07, University of Melbourne.

Kalb, G. and T.O. Thoresen (2009). Behavioural Microsimulation: Labour Supply and Childcare Use Responses in Australia and Norway. In New Frontiers in Microsimulation Modelling, eds.: A. Harding, P. Williamson and A. Zaidi.

Kaplow, L. (2007). Optimal Income Transfers. International Tax and Public Finance, 14, 
295-325.

Kapteyn, A., P. Kooreman and A. van Soest (1990). Quantity Rationing and Concavity in a Flexible Household Labor Supply Model. The Review of Economics and Statistics, 72, $55-62$.

Kornstad, T. and T.O. Thoresen (2004). Means-Testing the Child Benefit. The Review of Income and Wealth, 50, 29-49.

Kornstad, T. and T.O. Thoresen (2006). Effects of Family Policy Reforms in Norway: Results from a Joint Labour Supply and Childcare Choice Microsimulation Analysis. Fiscal Studies, 27, 339-371.

Kornstad, T. and T.O. Thoresen (2007). A Discrete Choice Model for Labor Supply and Child Care. Journal of Population Economics, 20, 781-804.

Mehlum, H., K. Moene and R. Torvik (2006). Institutions and the Resource Curse. The Economic Journal, 116, 1-20.

Michalopoulos, C. and P.K. Robins (2000). Employment and Child Care Choices in Canada and the United States. Canadian Journal of Economics, 33, 435-470.

OECD (2006a). OECD Factbook 2006 - Economic, Environmental and Social Statistics. Paris.

OECD (2006b). OECD Employment Outlook. Boosting Jobs and Incomes, Paris.

Powell, L.M. (2002). Joint Labor Supply and Childcare Choice Decisions of Married Mothers. The Journal of Human Resources, 37, 106-128.

Ribar, D.C. (1995). A Structural Model of Child Care and the Labor supply of Married Women. Journal of Labor Economics, 13, 558-597.

Rosen, S. (1996). Public Employment and the Welfare State in Sweden. Journal of Economic Literature, 34, 729-740.

Saez, E. (2002). Optimal Income Transfer Programs: Intensive versus Extensive Labor Supply Responses. The Quarterly Journal of Economics, 117, 1039-1073.

Statistics Norway (2007a). Births (http://www.ssb.no/english/subjects/02/02/10/fodte_en/).

Statistics Norway (2007b). Day-care centres (http://www.ssb.no/ ).

Van Soest, A. (1995). Structural Models of Family Labor Supply: A Discrete Choice Approach. Journal of Human Resources, 30, 63-88.

Walker, J. (1996). Funding Child Rearing: Child Allowance and Parental Leave. The Future of Children, 6, 122-136. 


\section{Appendix A The Norwegian behavioral simulation model}

The behavioral microsimulation model assumes that Norwegian families make choices among finite sets of job and care alternatives $B$ and $S$, for which utility is defined as:

$$
U\left(C_{k r}, H_{k}, Q_{r}, k, r\right)=v\left(C_{k r}, H_{k}, Q_{r}\right)+\varepsilon^{*}\left(C_{k r}, H_{k}, Q_{r}, k, r\right) \quad k \in B, \quad r \in S .
$$

where $C_{k r}$ is consumption/disposable income corresponding to job $k$ and childcare arrangement $r, H_{k}$ is annual hours of work in job $k$ for the mother, $Q_{r}$ is the quality of care alternative $r$, and $\varepsilon^{*}\left(C_{k r}, H_{k}, k, r\right)$ is a stochastic error term, which is allowed to vary both across combinations of care and job alternatives and across individuals, for instance accounting for unobserved care quality characteristics. The error terms are assumed to be both independent of observed characteristics and of each other, and distributed according to the extreme value distribution. ${ }^{27} v(.$.$) is the deterministic component of the utility function while$ $\varepsilon^{*}(.$.$) is the random component. The family's budget constraint is determined as described in$ equation (1) in Section 4.1.

The sets of job and care alternatives, $B$ and $S$, are represented by a common choice set $D=D(H, w, M)$, which denotes the number of alternatives that the families face for working hours and hours of care $H$. That is, a fixed link between hours of work and hours of care is assumed, except for home-working mothers who may use non-parental care alternatives, although at this stage this is suppressed in the notation. It can be useful to think of the alternatives within $D$ as packages: for working hours/hours of care $H$, families observe a number of job opportunities for the mother with wage rate $w$ and other job attributes, and a number of care alternatives with fees $M$ and care attributes, such as quality of care characteristics. Neglecting differences in wages and care prices across different choices for notational simplicity, it follows from the standard discrete choice model for utility maximizing behavior that the probability of choosing a job within $D$ can be written as:

$$
\varphi_{H}=\frac{\exp \left(v(H, w, M) \theta_{H}\right)}{\sum_{x} \exp \left(v(x, w, M) \theta_{x}\right)}
$$

where $\theta_{H}$ represents the number of combinations within $D$ and $v(H, w, M)$ represents the utility of choosing a care/work combination with hours $H$.

Equation (A.2) shows that the choice model is analogous to a multinomial logit model, where the representative utility terms are weighted with the number of opportunities $\left(\theta_{H}\right)$ at that utility, see also Dagsvik and Strøm (2006). However, as these opportunity densities are

\footnotetext{
${ }^{27}$ This means that choices need to satisfy the Independence from Irrelevant Alternatives (IIA) property.
} 
not observed, the empirical strategy implies estimating parameters reflecting differences in the number of opportunities across different choices along with parameters of the utility function.

In Kornstad and Thoresen (2007) the choice setting is further simplified by addressing choices between three types of care and five categories of working hours/hours of care. Let $m$ symbolize the three modes of care: care at centers $(m=1)$; care by other paid providers $(m=2)$; and own/parental care $(m=3)$. Jobs are divided into groups according to working hours. The model distinguishes non-participation $(j=1)$; three levels of part-time work, corresponding to 1-16 hours per week $(j=2), 17-24$ hours per week $(j=3)$ and 25-32 hours per week $(j=4)$; and full-time work at over 32 hours per week $(j=5)$. Then $P_{h j m}$ defines the probability that household $h$ chooses a job with hours of work in group $j$ and a childcare arrangement in mode $m$ :

$$
P_{h j m}=\frac{\exp \left(v\left(\tilde{C}_{h j m}, \tilde{H}_{j}, X_{h}\right)+\log \left(n_{j m} / n\right)\right)}{\exp \left(v\left(\tilde{C}_{h 13}, \tilde{H}_{1}, X_{h}\right)+\log n_{13}\right)+\sum_{i=1}^{5} \sum_{l \in \Omega_{h}} \exp \left(v\left(\tilde{C}_{h i l}, \tilde{H}_{i}, X_{h}\right)+\log n_{i l}\right)},
$$

where $j m=13$ represents the home care (no market work) alternative, and

$$
\Omega_{h}=\left\{\begin{array}{ll}
(1) & \text { if household } h \text { is constrained in the market for care at centers } \\
(1,2) & \text { otherwise }
\end{array} .\right.
$$

$\tilde{H}_{j}$ is the median working time in hours of work group $j, \widetilde{C}_{j m}$ is consumption corresponding to working time $\tilde{H}_{j}$ and $X_{h}$ is a taste-modifying variable. The key notion of (latent) differences in choice sets is captured by $\Omega_{h}$, stating some households have more limited choices, as center-based care is not available to them, and by the choice opportunities $n_{j m}$, which indicate that the number of opportunities in each care and work category may vary compared to the baseline $(n)$. An unobserved individual effect (random effect) is introduced in the representation of wages.

The deterministic part of preferences is represented by a "Box-Cox" type utility function:

$$
v\left(\tilde{H}_{j}, \tilde{C}_{h j m}\right) \equiv \gamma_{0} \frac{\tilde{C}_{h j m}^{\alpha_{1}}-1}{\alpha_{1}}+\frac{\left(1-\frac{\tilde{H}_{j}}{T}\right)^{\alpha_{2}}-1}{\alpha_{2}} X_{h} \beta,
$$

where $T=8760$ is the total number of annual hours, $\gamma_{0}, \alpha_{1}, \alpha_{2}$ and $\beta$ are parameters, and $X_{h}$ is 
the number of children below 19 years of age. The utility function is quasi-concave if $\alpha_{1}<1$ and $\alpha_{2}<1$. If $\alpha_{1} \rightarrow 0$ and $\alpha_{2} \rightarrow 0$, the utility function converges to a log-linear function.

\section{Appendix B The Australian behavioral simulation model}

The behavioral microsimulation model assumes that Australian families make choices among a finite set of hours worked, for which utility is defined as:

$$
U\left(C_{h_{1} h_{2}}, h_{1}, h_{2}\right)=v\left(C_{h_{1} h_{2}}, h_{1}, h_{2}\right)+\varepsilon^{*}\left(h_{1}, h_{2}\right) \text { with } h_{1} \in\left\{0, h_{11}, \ldots, h_{1 n}\right\}, h_{2} \in\left\{0, h_{21}, \ldots, h_{2 m}\right\} .
$$

where $C_{h_{1} h_{2}}$ is consumption/disposable income (exclusive of childcare expenditure) corresponding to the male partner working $h_{1}$ hours and the female partner working $h_{2}$ hours and $\varepsilon^{*}\left(h_{1}, h_{2}\right)$ is a stochastic error term, which is allowed to vary both across combinations of hours of work of both partners and across individuals. The error terms are assumed to be independent of observed characteristics and of each other, and are distributed according to the extreme value distribution. ${ }^{28} v(.$.$) is the deterministic component of the utility function while$ $\varepsilon^{*}(.$.$) is the random component. The family's budget constraint is determined as described in$ equation (2) in Section 4.1. Childcare is only included through the budget constraint.

It follows from the standard discrete choice model for utility maximizing behavior that the probability of choosing labor supply $h_{1}$ and $h_{2}$ can be written as:

$$
P_{h_{1} h_{2}}=\frac{\exp \left(v\left(C_{h_{1} h_{2}}, h_{1}, h_{2}\right)\right)}{\sum_{i=0}^{n} \sum_{j=0}^{m} \exp \left(v\left(C_{h_{1 i} h_{2 j}}, h_{1 i}, h_{2 j}\right)\right)}
$$

The deterministic part of preferences is represented by a quadratic utility function:

$$
\begin{gathered}
v\left(C_{h_{1} h_{2}}, h_{1}, h_{2}\right)=\beta_{C}\left(C_{h_{1} h_{2}}-\gamma_{1}-\gamma_{2}\right)+\beta_{1} h_{1}+\beta_{2} h_{2}+\alpha_{C C}\left(C_{h_{1} h_{2}}-\gamma_{1}-\gamma_{2}\right)^{2}+\alpha_{11} h_{1}^{2}+\alpha_{22} h_{2}^{2}+ \\
\alpha_{C 1}\left(C_{h_{1} h_{2}}-\gamma_{1}-\gamma_{2}\right) h_{1}+\alpha_{C 2}\left(C_{h_{1} h_{2}}-\gamma_{1}-\gamma_{2}\right) h_{2}+\alpha_{12} h_{1} h_{2}
\end{gathered}
$$

where $\alpha$. and $\beta$. are preference parameters and $\gamma_{1}$ and $\gamma_{2}$ are the fixed cost of working parameters to be estimated (where the indices 1 and 2 denote the husband and wife respectively). The fixed cost is zero when the relevant person is not working. Observed heterogeneity can be included by allowing $\beta_{1}, \beta_{2}, \beta_{\mathrm{C}}, \gamma_{1}$ and $\gamma_{2}$ to depend on personal and household characteristics. Unobserved heterogeneity can be added to $\beta_{1}, \beta_{2}, \beta_{C}$, and $\gamma_{2}$, in the form of a normally distributed error term with zero mean and unknown variance. The model is estimated using simulated maximum likelihood. In estimation, the unobserved heterogeneity parameters were found to be insignificant and were dropped.

\footnotetext{
${ }^{28}$ This means that choices need to satisfy the Independence from Irrelevant Alternatives (IIA) property.
} 
Probability distributions of labor supply for Australia are obtained using a userspecified number of random draws (100 in our case) rather than use equation B.2 since this allows us to calibrate to observed hours. The deterministic component of utility, $v\left(C_{h_{1} h_{2}}, h_{1}, h_{2}\right)$, is obtained using the parameter estimates of the quadratic preference function. To generate the random component of utility, a draw is taken from the distribution of the error term for each hours level (an Extreme Value Type I distribution). The utility-maximizing hours level is found by adding the two components of utility for each hours level and choosing the hours with the highest utility. Draws from the error terms are taken conditionally on the observed labor supply; that is, they are taken in such a way that the optimal pre-reform labor supply is equal to the actually observed labor supply. As a result, the post-reform labor supply outcome is computed conditional on the observed pre-reform labor supply. Using the repeated draws, an empirical probability distribution for the hours of work can be constructed at the individual level and aggregated up to the population level. The probability distribution can then be used to simulate expected labor supply responses or changes in expenditure at the individual level which can then again be aggregated up to the population level. 